\title{
EL PLAN CONCERTADO \\ DE PRESTACIONES BÁSICAS \\ DE SERVICIOS SOCIALES EN ESPAÑA \\ (Once años del Plan Concertado)
}

\section{Antonio Gutiérrez Resa}

Universidad de Zaragoza

E-mail: agresa@posta.unizar.es

\begin{abstract}
RESUMEN
La intervención público-estatal ha sido una constante en materia de bienestar social y servicios sociales, y habiendo acabado el siglo xx estimamos conveniente que el Estado siga siendo la garantía básica de aquellas personas que padecen dificultades, junto al mercado y, sobre todo, junto a las entidades sin ánimo de lucro. El Plan CCB o comunidad cristiana de bienes es la fuente de inspiración de los servicios sociales de base o comunitarios en los años sesenta. Constituye la tradición española más inmediata que fue capaz de organizar los citados servicios como beneficencia y caridad. A partir de la reinstauración democrática y algunos años después (1988) se desarrolla una red pública de servicios sociales generales y para todos, que comienza a consolidarse con un nivel de prestaciones básicas en la década de los noventa. El acuerdo entre la Administración Central, Comunidades Autónomas y Entes Locales haría posible la red básica de servicios sociales públicos. Con el acuerdo nace el Plan Concertado (1988) y se consolida en torno al año 1995. Sobrepasados los diez años del Plan Concertado (1988-1998), la experiencia acumulada y la información disponible permiten albergar transformaciones que lo adapten a las nuevas necesidades de la sociedad española. Las exigencias de nuevas necesidades y los servicios sociales para todos marcan la pauta de lo que debe constituir el avance del Plan Concertado.
\end{abstract}

\section{INTERVENCIÓN DEL ESTADO, BIENESTAR SOCIAL Y SERVICIOS SOCIALES (CONTEXTO)}

Tras la Segunda Guerra Mundial, los ciudadanos del mundo occidental industrializado gozaron de unos niveles de bienestar debido, en buena parte, a

\section{Reis}


la intervención decidida del Estado en materia de sanidad, educación, pensiones y servicios sociales.

La intervención del Estado se hacía presente en lograr el pleno empleo, servicios sociales universales y un nivel mínimo de vida garantizado, mientras la familia se hacía cargo de la mayoría de los cuidados sociales de sus miembros.

En España los antecedentes más cercanos del Estado de Bienestar los situamos en los años sesenta, destacando el importante peso del sector privado en la prestación de servicios sanitarios, educativos y sociales, así como de la procura de los mismos por parte de la Iglesia católica. Precisamente en el año 1957, Cáritas Nacional crea la Sección Social con el claro objetivo de superar la beneficencia pública y desarrollar los servicios sociales. Y en el año 1963 la protección pública crea el sistema de la Seguridad Social con prestaciones «básicas» y "complementarias», incluidas en estas últimas los servicios sociales y la asistencia social de la Seguridad Social.

El Estado de Bienestar español trataba de adecuarse a los países de su entorno, aunque las circunstancias políticas dificultaron posiblemente alcanzar un mayor ritmo en las reformas sociales. Hasta los años setenta, incluida España en el mundo industrial, se habían seguido los dictámenes del economista John Maynard Keynes, quien había colocado al Estado como inversor financiero central de la economía de las naciones, además de moderador ante el desempleo o ante los desequilibrios económicos. También en los Estados Unidos, tras la crisis de los años treinta del pasado siglo, fue el gobierno de Franklin Roosevelt el que con el New Deal inventa el moderno Estado Social para salir de la crisis que había provocado el impulso globalizador de la economía mundial.

En torno a los años 1970 cambian las cosas. La realidad social es bastante más compleja porque no sólo disminuyen los puestos de trabajo, sino que el sistema productivo exige mayor diferenciación laboral, ciclos de vida diversos, mayor flexibilidad, e independencia y empleo para las mujeres ${ }^{1}$. El Estado, el mercado laboral y la propia familia buscaban fórmulas de entendimiento que lograran mantener el bienestar alcanzado y caminos que condujeran a una transformación del Estado Social. Las miradas se dirigían a neoliberales como Milton Friedman o August Hayek, para quienes el Estado es un mero guardián del orden que deja libres a las empresas privadas. En el caso de España, la intervención del Estado en aras de un mayor bienestar social es evidente durante la década de los años setenta. Los dos primeros ejemplos que confirman lo que decimos son la Ley General de Educación de 1970 (Ley Villar Palasí) y la Ley de Reforma y Perfeccionamiento de la Seguridad Social de 1972. Aun con todo, el sector privado seguía teniendo un importante peso en la educación (infantil) y en la sanidad. Se mantenían los servicios sociales y la asistencia social de la Seguridad Social, diferenciados de la asistencia-beneficencia del Estado.

1 Gosta Esping-Andersen, «El Estado de Bienestar», en Tomás Fernández García (coord.) (1998), Estado de Bienestar: perspectivas y limites, Colección Estudios, Ediciones de la Universidad de Castilla-La Mancha, pp. 28-30. 


\section{CUADRO 1}

«Servicios Sociales»/Instituciones, antes de la Constitución de 1978

\begin{tabular}{ll}
\hline Beneficencia & Admón. Central, Diputaciones y Ayuntamientos \\
\hline INAS & Admón. Central (M. o de Gobernación: Interior) \\
\hline Serv. Sociales de la Seg. Social & Varios \\
\hline Serv. Comunes de la Seg. Social & SEREM, SAP, SSMT, etc. \\
\hline
\end{tabular}

En España se reordena el Estado de Bienestar con la aprobación de la Constitución democrática de 1978. El nuevo marco constitucional hace mención expresa de los servicios sociales en al art. 20 y los relaciona con las personas de la tercera edad. En la Constitución de 1978 también se hace mención de la asistencia social, aunque el desarrollo de la misma lo harían las Comunidades Autónomas con la aprobación de sus correspondientes leyes en materia de asistencia social y servicios sociales. No obstante, en la Constitución se definen los servicios sociales como "conjunto de prestaciones que se le ofrece a la Comunidad al objeto de conseguir la prevención o eliminación de las causas que llevan a la marginación».

Desde la Constitución de 1978 se han sucedido leyes de servicios sociales en las Comunidades Autónomas hasta la Ley Reguladora de Bases de Régimen Local (1985), que establece competencias en materia de servicios sociales para aquellos Ayuntamientos con más de 20.000 habitantes. Comprobamos, una vez más, que la Administración del Estado interviene en materia de bienestar social, de servicios sociales, y que da prestaciones.

\section{CUADRO 2}

\section{Principales etapas de los Servicios Sociales en España}

1978-1983: Etapa de confusión pero también de creación de las primeras Concejalías de Servicios Sociales.

1983-1985: Etapa de las primeras transferencias a las Comunidades Autónomas. Primeras leyes, convenios, etc.

1985-1987: Etapa de planificación territorial y coordinación de Comunidades Autónomas y Diputaciones con los Entes Locales. Aprobación de las Ley de Bases de Régimen Local.

1987-1991: Etapa de conclusión legislativa autonómica en materia de servicios sociales. Creación del Ministerio de Asuntos Sociales e inicio del Plan Concertado.

1991-1996: Consolidación del Plan Concertado y reajuste ministerial. Ministerio de Trabajo y Asuntos Sociales.

1996-1998: El Plan Concertado cumple diez años. 
Las citadas leyes de servicios sociales de las Comunidades Autónomas distinguen los servicios sociales de base o generales con las correspondientes prestaciones básicas. No obstante, faltaba precisar cómo organizar y financiar los servicios sociales en su categoría de generales o básicos. Aunque la intervención del Estado se descentra, sería el Ministerio de Trabajo y Seguridad Social con cada Comunidad Autónoma quien establece en 1988, a través del convenio administrativo, una cooperación económica y técnica con los Entes Locales. El objetivo consistía en financiar una red de servicios sociales municipales que garantizara unas prestaciones básicas a los ciudadanos en situación de necesidad. Al conjunto de la operación se le llamó Plan Concertado para el Desarrollo de las Prestaciones Básicas de Servicios Sociales Locales. Las prestaciones que garantizaba el Plan eran las siguientes: información y orientación, ayuda a domicilio, alojamiento y convivencia, y prevención e inserción social.

Hemos dejado constancia, aunque sea de manera resumida, de la intervención del Estado, incluido nuestro país, en la constitución y desarrollo del bienestar social, con una clara referencia a los servicios sociales. En la actualidad, el panorama que ofrece el sistema público de servicios sociales y asistencia social en España es el siguiente: se configura como un conjunto de servicios dirigidos a toda la población, de responsabilidad pública y que constituyen tanto prestaciones técnicas como prestaciones de carácter económico. Se dirigen a todos por ser universales, aunque se da prioridad a aquellos colectivos con carencias más graves. Por ser de responsabilidad pública está garantizado el sistema de tales servicios, así como su coordinación y promoción. Las prestaciones técnicas comprenden tanto las de carácter económico que se facilitan de modo coyuntural como los programas, los recursos y los equipamientos específicos.

La configuración organizativa que presenta el sistema público de servicios sociales en España tuvo su punto de inflexión en la descentralización administrativa que se produjo a partir de la Constitución de 1978, con la estructuración de las Comunidades Autónomas y la asunción de competencias que en materia de asistencia social les son asignadas ${ }^{2}$. Todas las leyes autonómicas de servicios sociales tienen por objeto implantar un sistema público de servicios sociales, que ponga a disposición de las personas y los grupos en los que se integran recursos, actividades, prestaciones y equipamientos, dotados de una organización para el logro de su pleno desarrollo. Según las leyes, los servicios sociales se estructuran en dos niveles:

a) Servicios sociales dirigidos a toda la población, que reciben distintas denominaciones: Servicios Sociales de Base, Servicios Sociales Comunitarios, Servicios Sociales Generales, Servicios Sociales de Atención Primaria. Integran prestaciones básicas y específicas.

2 Antonio Gutiérrez Resa y Jordi Garcés Ferrer (coords.) (2000), Los Servicios Sociales en las Comunidades y Ciudades Autónomas, Tirant Lo Blanch, Valencia. 
b) Servicios sociales dirigidos a colectivos específicos de población, y denominados también Servicios Sociales Especializados por no ser comunitarios, estar distanciados del domicilio e identificarse con las diferencias personales y características grupales de los usuarios.

Los servicios sociales de base o generales informan y orientan sobre derechos y recursos (individuos, grupos, instituciones); realizan prevención e inserción social y familiar (personas y colectivos en situación de riesgo o marginación); prestan ayuda a domicilio (personas y familias que padecen situaciones que lo requieren); dan prestaciones de alojamiento y convivencia (personas que carecen de ambiente familiar idóneo). Los servicios sociales de base también incluyen prestaciones específicas a colectivos (infancia, juventud, tercera edad, mujeres, minorías étnicas, transeúntes, etc.). Se gestionan a través de los centros de servicios sociales y a través de centros comunitarios (centros de acogida, centros de día, centros ocupacionales, etc.) de las Corporaciones Locales.

Los servicios sociales especializados se organizan y gestionan, con titularidad de la Comunidad Autónoma, en función de colectivos de población a los que van dirigidos: infancia, mayores, mujer, etc. La especialización se identifica con las diferencias de los usuarios por cuestiones de edad, sexo y otras características personales con presunta proyección social. Los equipamientos en función de los usuarios pueden ser algunos de los siguientes: centros de día para adultos, centros de día para menores, centros de día para la comunicación social (ancianos, jóvenes, mujeres, etc.), residencias, centros ocupacionales (discapacitados, parados, transeúntes, inmigrantes, etc.) y hogares protegidos (menores, discapacitados, drogodependientes), centros de inserción social para drogodependientes, centros para personas discapacitadas (rehabilitación médico-funcional, atención psicosocial, formación/recuperación profesional, estimulación precoz).

Hasta aquí hemos hecho una presentación sobre la intervención del Estado en la constitución y desarrollo del Estado de Bienestar. La expresa referencia a los servicios sociales es obvia porque forman parte del conjunto de sistemas del Estado de Bienestar. Y en el caso español vamos a ver inmediatamente que los antecedentes más inmediatos de los servicios sociales los encontramos en los años sesenta. En los años sesenta del pasado siglo, y desde el ámbito privado, se llegó a intentar poner en práctica un Plan de asistencia a los ciudadanos. Plan que, hace treinta años, trataba de organizar la beneficencia y los servicios sociales especiales para marginados. Sin embargo, la intervención del Estado ha hecho posible que en materia de servicios sociales se haya producido una evolución positiva de los mismos hasta llegar a acordar, en 1988, el Plan Concertado de Prestaciones Básicas de Servicios Sociales en España. 


\section{CUADRO 3}

Tipología de los Servicios Sociales en España

\begin{tabular}{|c|c|c|c|c|}
\hline & \multicolumn{2}{|c|}{ Servicios Sociales generales } & \multirow{2}{*}{$\begin{array}{c}\text { Servicios } \\
\text { Sociales } \\
\text { especializados }\end{array}$} & \multirow{2}{*}{$\begin{array}{c}\text { Prestaciones } \\
\text { económicas } \\
\text { individualizadas }\end{array}$} \\
\hline & $\begin{array}{l}\text { Prestaciones } \\
\quad \text { básicas }\end{array}$ & $\begin{array}{c}\text { Prestaciones } \\
\text { básicas específicas }\end{array}$ & & \\
\hline \multirow[t]{3}{*}{ Caracteristicas } & $\begin{array}{l}\text { Dirigidos a toda } \\
\text { la población }\end{array}$ & $\begin{array}{l}\text { Dirigidos a } \\
\text { determinados } \\
\text { colectivos }\end{array}$ & $\begin{array}{l}\text { Dirigidos a deter- } \\
\text { minados colectivos }\end{array}$ & $\begin{array}{l}\text { Menor peso que las } \\
\text { prestaciones en } \\
\text { especie }\end{array}$ \\
\hline & $\begin{array}{l}\text { Se prestan cerca } \\
\text { del propio } \\
\text { domicilio }\end{array}$ & $\begin{array}{l}\text { Se prestan cerca } \\
\text { del domicilio }\end{array}$ & $\begin{array}{l}\text { Se prestan lejos del } \\
\text { domicilio en Cen- } \\
\text { tros especializados }\end{array}$ & $\begin{array}{l}\text { Van dirigidas a } \\
\text { determinados indi- } \\
\text { viduos/colectivos en }\end{array}$ \\
\hline & $\begin{array}{l}\text { Dependen de } \\
\text { entes públicos } \\
\text { locales }\end{array}$ & & $\begin{array}{l}\text { Dependen de entes } \\
\text { públicos y priva- } \\
\text { dos }\end{array}$ & $\begin{array}{l}\text { situación de extre- } \\
\text { ma necesidad }\end{array}$ \\
\hline \multirow[t]{4}{*}{ Prestaciones } & $\begin{array}{l}\text { Información } \\
\text { y orientación }\end{array}$ & $\begin{array}{l}\text { Prevención e } \\
\text { inserción }\end{array}$ & $\begin{array}{l}\text { Rehabilitación } \\
\text { médico-funcional }\end{array}$ & $\begin{array}{l}\text { Pensiones de } \\
\text { asistencia social }\end{array}$ \\
\hline & $\begin{array}{l}\text { Prevención e } \\
\text { inserción social }\end{array}$ & $\begin{array}{l}\text { Ayuda a } \\
\text { domicilio }\end{array}$ & $\begin{array}{l}\text { Atención } \\
\text { psicosocial }\end{array}$ & $\begin{array}{l}\text { Subsidio de movili- } \\
\text { dad y compensa- } \\
\text { ción }\end{array}$ \\
\hline & $\begin{array}{l}\text { Ayuda a } \\
\text { domicilio }\end{array}$ & $\begin{array}{l}\text { Convivencia } \\
\text { familiar y social }\end{array}$ & $\begin{array}{l}\text { Formación y/o } \\
\text { recuperación } \\
\text { profesional }\end{array}$ & $\begin{array}{l}\text { Pensiones no } \\
\text { contributivas }\end{array}$ \\
\hline & $\begin{array}{l}\text { Prestaciones de } \\
\text { alojamiento y } \\
\text { convivencia }\end{array}$ & & $\begin{array}{l}\text { Estimulación } \\
\text { precoz }\end{array}$ & \\
\hline
\end{tabular}

Programa de Rentas Mínimas de Inserción (Comunidades Autónomas)

Fuente: José Barea Tejeiro³.

\section{DEL PLAN CCB AL PLAN CONCERTADO (ANTECEDENTES, ORIGEN Y DESARROLLO DEL PLAN CONCERTADO DE PRESTACIONES BÁSICAS)}

En un adelanto de lo que explicaremos en este apartado, comenzaremos por decir que los denominados hoy servicios sociales de base o comunitarios tienen un pasado. Se comenzaba a hablar de los servicios sociales comunitarios

3 José Barea Tejeiro (dir.) (1997), El gasto público en servicios sociales en España, Ministerio de Trabajo y Asuntos Sociales, Madrid, p. 83. 
en los inicios de la década de los sesenta, aunque, eso sí, los concibieran como servicios sociales especiales o para marginados, y no como ahora destinados a todos los ciudadanos.

La instauración de la democracia no invalida más tarde la necesidad de desarrollar los servicios sociales comunitarios. Sin embargo, no estaba claro el modo de conseguirlo porque en el año 1982 se frustra el intento de crear una Ley Nacional de Servicios Sociales y en el mismo año se aprueba la Ley 6/1982, de 20 de mayo, sobre Servicios Sociales del País Vasco. Al año siguiente se aprobaba la Ley sobre Servicios Sociales de Navarra.

Después de algunos años de desarrollo autonómico, los servicios sociales comunitarios vuelven a estar en el candelero a pesar de que los servicios sociales especializados marcaron la pauta de las primeras leyes autonómicas sobre la materia ${ }^{4}$. Posiblemente se constataba la necesidad de acordar unos mínimos o establecer una red básica de servicios sociales, después de comprobar que los servicios sociales especializados, y más desarrollados tradicionalmente, estaban determinados por variables socioeconómicas concretas en cada Comunidad Autónoma.

La necesidad de aunar esfuerzos para ofrecer una red básica de servicios sociales a la totalidad de los ciudadanos en todas las Comunidades Autónomas llegó a permitir que en el año 1988 se iniciara el Plan Concertado. De este modo se lograba, junto al sistema sanitario, educativo y de pensiones, crear por primera vez un sistema básico de prestaciones en servicios sociales.

\subsection{Servicios sociales comunitarios o para marginados: el Plan CCB de los años sesenta}

Cuando hablamos hoy de servicios sociales comunitarios, tal y como hemos dicho en el punto anterior, entendemos por semejantes servicios las prestaciones básicas que se ofertan colectivamente. Ahora bien, al rastrear el concepto de "comunitario", nos encontramos con que va unido, entre las varias acepciones, al de acción social, habiéndose practicado ambos conceptos (acción social y comunitaria o desarrollo comunitario) en torno a los años sesenta en España. El paso de los años ha consolidado el concepto de comunidad, en donde cobran especial sentido los conceptos de integración, adaptación, participación, identidad cultural o equipamientos infraestructurales.

Los servicios sociales comunitarios también han sido objeto de atención y promoción en otros países como Francia y Estados Unidos. En nuestro vecino país, entre 1971-75, el VI Plan francés concedía una nueva dimensión a la

${ }^{4}$ M. Gaviria, M. Laparra y M. Aguilar (1992), «Los servicios sociales generales. Un sistema sin objeto" (en coop.), Evolución social en España (1990), Instituto Sindical de Estudios, Madrid. 
acción social. Se iniciaba la nueva fase de la planificación social, que superaba el ámbito sanitario atendido con anterioridad y que apuntaba ahora a diferentes ámbitos del conjunto de la comunidad. La planificación de las funciones colectivas o comunitarias y la autonomía de la persona venían a ser las dos ideas fundamentales del VI Plan. Por ello las actuaciones estaban dirigidas tanto a la comunidad en general como a sectores determinados. En suma: ancianos, minusválidos y emigrantes; madres trabajadoras con hijos pequeños, y jóvenes que se incorporaban al trabajo alejados de la familia; acción global preventiva y de promoción dirigida a los barrios, distritos o municipios rurales. En Norteamérica, la Ley de Oportunidades para la Promoción Social de 1964 le da un nuevo sentido a la acción social, promocionando la Acción Comunitaria del mundo subdesarrollado, a través del acuerdo, y sin que el trabajador social ejerza el papel directivo. Las actuaciones iban dirigidas prioritariamente contra la pobreza, tratando de captar la máxima participación. En concreto: educación preescolar, servicios de asesoría jurídica y planificación familiar ${ }^{5}$.

En España es el Plan CCB (1961-1964) quien señala con más empeño la necesidad de la acción social comunitaria. Se trataba de establecer una comunicación de bienes, desde la inspiración cristiana, de entre los que poseían con quienes no disponían de nada. Un Plan (el Plan CCB o comunidad cristiana de bienes) que respondía al encargo que le hacía a Cáritas Española la Comisión Episcopal de Caridad y Asistencia Social de la Iglesia (1961) para realizar el primer estudio sociológico sobre España. Allí quedaba reflejada la necesidad de la acción social comunitaria que había de superar el asistencialismo practicado con ocasión de la Ayuda Social Americana. Y al mismo tiempo se criticaban en el informe los Planes de Desarrollo y el crecimiento no integrado porque ignoraban los aspectos sociales.

El Plan CCB surgió en una década que marcó el futuro de nuestro país, por todo un conjunto de circunstancias. Mencionaremos únicamente dos de ellas. España partía hacia el desarrollo industrial con un Plan de Estabilización Económica (1959) y más tarde con unos Planes de Desarrollo (1964). Y, en segundo lugar, es el decenio en el que la población campesina desciende mientras se cuestiona el modelo de agricultura tradicional. El saldo del éxodo rural llegó a ser de 1.900 .559 trabajadores $(1960-1970)^{6}$. Si el éxodo rural mostraba bien a las claras que el campo no daba para mantener el nivel de vida deseado por el número de sus habitantes, las ciudades que los acogían pronto necesitaron planificar y desarrollar nuevos servicios.

Cáritas Española, encargada del Plan CCB, se hacía eco en el primer número de la revista de Documentación Social de los problemas capitales dentro de lo social: la vivienda en las zonas suburbiales de las grandes ciudades y

5 F. Villota (1973), Problemas actuales de los servicios de bienestar social, Ed. Fundación FOESSA, Euroamérica, Madrid, pp. 127-168/169-189.

${ }^{6}$ En el año 1957, la población activa española era de 11.285.986. En el sector agrícola: 4.783.339; en el sector industrial: 3.335.025, y en el sector servicios: 3.166 .622 (cfr. Documentación Social, núm. 4). 
las causas de las migraciones interiores. La revista, cuyo primer número versaba sobre «Lo social en Cáritas» (1958), la crea el Dr. Rogelio Duocastella junto con la Sección Social de Cáritas Española. En el citado primer número de la revista de Documentación Social es donde aparecen los Centros Sociales como una de las fórmulas "para canalizar una acción social en las zonas económicamente débiles». De este modo trataban de incorporar a los beneficiarios a la gestión de los servicios. Los Centros Sociales colocados en los suburbios los transformarían en barrios por llegar a canalizar una vida social comunitaria. Eran claramente centros de servicios, impulsores de la vida social, representativos y forjadores de las primeras células de una comunidad humana local. Centros que estaban próximos a los ciudadanos ofreciendo un mismo lugar de reunión, un conjunto de servicios, permanente y con personal capacitado. Otras fórmulas, además de los centros sociales, eran los hogares de empleados y trabajadores, así como las residencias para ancianos.

El conjunto de los servicios sociales, como prestaciones que citaba Cáritas Española para el desarrollo comunitario o como servicios sociales de comunidad, eran: "guarderías o casas de infancia, cooperativas de consumo, cooperativas de crédito para la adquisición de ciertos artículos o servicios, servicio de ahorro popular, colonias de vacaciones, comedores o cantinas populares, servicios de orientación jurídico-social, escuelas de hogar, nocturnas, para jóvenes, escuelas de aprendizaje, bibliotecas populares, cursillos, conferencias, residencias de obreros, servicios asistenciales de migración». También se hablará, unos años más tarde, de la necesidad de crear servicios sociales comunitarios en las ciudades tales como Instalaciones Deportivas, Salas de Recreo y Convivencia, Zonas Verdes ${ }^{7}$.

Con los Centros Sociales se trataba de crear núcleos, comunidades de vida social, tanto para los que emigraban como para aquellos otros que decidían permanecer en el campo, aun a sabiendas de que disminuía su nivel de vida. La adaptación a uno u otro de los ambientes era diferente, como lo era para aquellos que de las zonas rurales del sur emigraban a las zonas industriales del norte de España. Los servicios sociales eran los mecanismos que, en las zonas deprimidas, formaban parte de los programas destinados a mantener la cohesión social de aquellas personas afectadas por los desajustes rurales o urbanos ${ }^{8}$. En semejante tarea llegaron a participar, entre otros, entidades privadas como las Cajas de Ahorro, Sindicatos y Montepíos Laborales.

Hablamos de servicios sociales porque se citan así, aunque ya hemos anun-

Rogelio Duocastella, «Necesidad de una “Acción Social” en Cáritas Diocesanas», Rev. Documentación Social, núm. 1, Madrid, 1958, y «La promoción urbana y sus objetivos», por Antonio Del Valle, Rev. Documentación Social, núm. 1, marzo de 1966.

${ }^{8}$ Son servicios sociales, si se nos permite la expresión, para favorecer el desarrollo comunitario de zonas deprimidas, desarrollo que también apunta claramente en la dirección de combinar el mercado laboral con la cohesión social. Los Centros Sociales servían a tal efecto, y países como Francia ya disponía de 30 Centros Sociales en 1947 y de 160 en 1957, constituidos en Federation de Centres Sociaux de France (cfr. Documentación Social, núm. 2). 
ciado que deben ser entendidos en el contexto de la «asistencia social» como promoción humana y social de los necesitados. Es decir, acción social como nuevo concepto de caridad. Sin embargo, ya se llegaba a captar por entonces que los desajustes eran de tipo social, estructural y no sólo individual. Y aunque se habla de servicios sociales, son servicios sociales especiales (aunque comunitarios) por estar a disposición de los suburbios, de las zonas rurales más convencionales y comarcas subdesarrolladas, y de las migraciones. El resto de los servicios, o servicios sociales no especiales, debían cubrir la asistencia social laboral, sanitaria, judicial y administrativa.

El Estado, según el citado informe, debía asumir su responsabilidad, mientras la Iglesia a través de Cáritas hacía lo propio, siguiendo claras directrices para practicar lo que era de su competencia "por su propia naturaleza»: la acción de "asistencia sana y de promoción social de beneficencia». Era un modo efectivo de coordinación dentro de la Iglesia, y de invitación a la sociedad cristiana civil para que colaborara con Cáritas Española desde las Cáritas Diocesanas y Parroquiales. Consecuentemente, el Plan CCB «está al servicio de la acción caritativa de la Iglesia, de las comunidades cristianas diocesanas y su Jerarquía»". Queda claro que el telón de fondo lo constituía la práctica de la caridad, "que vivifica y anima las relaciones entre los hombres precisamente en las situaciones de sufrimiento». "Al Plan CCB lo que le preocupa especialmente era la caridad en cuanto es aplicada a un determinado tipo de situaciones y de relaciones, las que nacen precisamente de las situaciones de sufrimiento, haya o no haya un problema económico de por medio» ${ }^{10}$.

Las situaciones de sufrimiento que denunciaba Cáritas en los años sesenta eran la subalimentación que afectaba a tres millones de españoles, la vivienda, así como aquellos otros problemas de índole psicosocial que definían o constituían la creciente complejidad de la situación social. El Plan CCB se refería, entre otros, a la inadaptación social, neurosis, la crisis de la familia, crisis culturales y crisis sociales. Y para afrontar tales situaciones había que contar con el concurso de las nuevas técnicas eficaces. Se dirá que precisamente en la ayuda al necesitado es donde las ciencias sociales aplicadas han desarrollado una parte importante de su contenido; por ejemplo, «trabajo social», «ingeniería social», "trabajo de casos», "trabajo de grupos», "trabajo de comunidad», "programación social», etc. Por tales razones, «todas las técnicas sociales pueden y deben servir para que la acción eclesial caritativa de ayudar a los que sufren alcance un máximo de eficacia». Diremos finalmente que las técnicas sociales debían ir de la mano de una fundamentación teológica: la fundamentación quedaba constituida por «la caridad, el amor humano transformado en sobrenatural». Era lógico, decían, si se tiene en cuenta que la historia, la sociedad, caminan hacia la perfección final, sirviéndose del progreso y de la técnica como signo de eficacia. "Por eso Cáritas no es una asociación ni una organiza-

9 Cáritas Española (1965), Plan CCB, Ed. Euroamérica, Madrid, p. 21.

${ }_{10}$ Ibid. nota anterior. 
ción, sino la propia comunidad cristiana y su instrumento en la acción caritativa de puesta en común de bienes» ${ }^{11}$.

\subsection{Hacia un sistema público de Servicios Sociales}

Han pasado algunos años de lo apuntado por el Plan CCB en los años sesenta. Entretanto, se llegaba a la instauración democrática (1975) sin haber consolidado un sistema de protección social en materia de servicios sociales, y que había tenido su inicio en la década de los años sesenta, tras el Plan de Estabilización (1959).

Ni los proteccionistas Planes de Desarrollo (1964) ni, más tarde los primeros síntomas de la crisis en el inicio de la década de los años setenta, pusieron fácil a nuestra democracia desarrollar una red de servicios sociales comparable a la de otros países europeos. Bastaba comprobar la evolución de algunas variables como el PIB, la tasa de paro o el coste de la vida (1961-1982) para reafirmar la imperiosa necesidad de crear una red de servicios sociales de la sociedad del bienestar en España que paliara el empobrecimiento de los españoles ${ }^{12}$. Era necesario garantizar un nivel de bienestar mínimo a todo ciudadano, y a tal efecto debían contribuir unos servicios sociales colectivos, junto al seguro de desempleo y la sanidad pública. Era el contexto en el que se situaba entonces la discusión sobre los servicios sociales comunitarios, cuando ni el desarrollo económico, histórico y social de nuestro país habían propiciado hacer uso teóricopráctico de semejantes términos.

La paradoja estaba, por tanto, planteada entre un Estado de Bienestar en España y unos servicios sociales comunitarios que hasta la fecha no habían fraguado en prestaciones básicas para todos. Sin embargo, se había logrado un cambio importante de mentalidad: "el cambio de mentalidad se pone de relieve en una nueva formalización del bienestar en términos de desarrollo; este concepto desarrollista tiene un carácter positivo, se extiende más allá de los servicios facilitados a los necesitados, carga también el acento en la planificación del cambio social y en la provisión de los recursos esenciales para mantener y mejorar el funcionamiento social, y no sólo de los servicios de adaptación al individuo a la comunidad ${ }^{13}$. La política social del Estado de Bienestar iba dirigida a todos los ciudadanos sin excepción.

Tras la instauración de la democracia se intenta aclarar el concepto de los

11 Ibid. nota 9, p. 30. Las acciones concretas comunitarias, puestas en práctica por Cáritas, se centrarían en aquellas zonas más deprimidas por entonces de la geografía española. Un claro ejemplo lo constituyen los tres períodos del Plan Baza: 1954-1958-1963 (cfr. Demetrio CASAdo [1969], Plan Social Baza, Ed. Cáritas Española, Madrid).

12 J. L. García (1988), España. Economía, 2 vols., Ed. Espasa-Calpe, Madrid, p. 843.

13 C. SÁnChez (1979), «El bienestar social a través de la historia y su concepto actual», Rev. Documentación Social, núm. 36. 
servicios sociales, qué características deben tener, si se destinan a toda la población o no, si se entiende por servicios sociales cualquier tipo de prestaciones, si se subsumen en la asistencia social, si deben diferenciarse los pertenecientes a la Seguridad Social de aquellos otros servicios sociales públicos generales, si se identifican servicios sociales y bienestar social, o si son complementarios de las prestaciones individuales de la Seguridad Social ${ }^{14}$. La discusión provenía de que en la época franquista había existido una asistencia social pública de carácter general, unos servicios sociales y asistenciales especializados por sectores, y los servicios sociales y asistencia social de la Seguridad Social. En 1977 todavía se seguía hablando de la asistencia social como uno de los servicios que deben prestar los municipios. «Las instituciones adecuadas son las guarderías o casacuna, los asilos y residencias y los consultorios sociales o centros sociales» ${ }^{15}$.

Hasta ahora los servicios sociales existentes (1974) eran una protección complementaria de la Seguridad Social. Se trataba de prestaciones técnicas, no económicas, y reglamentadas, sobre todo, en las áreas de «Higiene y Seguridad del Trabajo», "Medicina Preventiva», "Reeducación y Rehabilitación de Minusválidos», "Acción Formativa» y otras; también estaban los servicios sociales de empresa junto a la acción social que canalizaban diferentes organismos, y aquellos otros que intentaban superar la Beneficencia y Asistencia Social del Estado. Y según el tipo de usuarios estaban los servicios sociales especializados: Obra de Protección de Menores, Patronato de Protección de la Mujer, Patronato de Igualdad de Oportunidades, etc.

Pasados los años, se sigue hablando de «Servicios Sociales en el desarrollo comunitario", precisamente porque lo exigen las circunstancias y porque va en aumento el número de pobres y marginados. "Porque el desarrollo comunitario en nuestro país ha sido casi siempre ignorado, y en ese "casi", perseguido" ${ }^{16}$. Los servicios sociales se quieren hacer extensivos a toda la población con el objetivo, ya conocido, de lograr el desarrollo personal y colectivo a nivel popular, y de modo participativo. Por hacerse extensivos a toda la población, sus principios básicos serán: universalización, normalización (evitando servicios sociales que discriminen a los usuarios), racionalidad, descentralización y participación. En definitiva, se trataba de estructurar un Sistema Público de Servicios Sociales. «Sistema en el que juegan un importantísimo papel tanto la elevación del nivel de bienestar de la población como la profundización en el proceso democrático y de cambio social, con la consiguiente crítica y movilización popular $»^{17}$.

${ }^{14}$ Cfr. Documentación Social, núm. 34: «El Bienestar Social y los Servicios Sociales».

15 C. SÁnChez (EDIS) (1978), "Los servicios que debe prestar el municipio», Rev. Documentación Social, núm. 29.

16 P. Fernández (1983), «Política social», Rev. Documentación Social, núm. 53.

17 F. J. Navarro (1979): «El bienestar social y los servicios sociales», Rev. Documentación Social, núm. 36. Años más tarde (1981), Rosa DoméNeCH, en «Servicios Sociales para Todos» (Rev. Documentación, núm. 44), repite el planteamiento pero añade la experiencia de los servicios sociales del Ayuntamiento de Barcelona. En él, los Centros Municipales de Servicios Sociales «son el instrumento organizativo de base y de atención directa del ciudadano». 
En el año 1983 se desconocía todavía el papel que les iba a corresponder a los Servicios Sociales y a la Asistencia Social, al tiempo que caracterizan a los primeros por la «inexistencia de un criterio básico... y, por tanta carencia de una legislación homogénea y de una política coherente al respecto». Sin embargo, se seguía hablando como antaño de revitalizar el desarrollo comunitario y la participación y organización de la comunidad ${ }^{18}$.

\subsection{Servicios Sociales especializados en las CC.AA.}

El desarrollo autonómico, después de instaurada la democracia, puso de manifiesto el auténtico enredo que se había formado en torno a los términos: acción social, asistencia social, bienestar social, servicios sociales, mientras «la beneficencia, al parecer, quedaba superada».

La necesidad de poner a punto los servicios sociales comunitarios, en una situación de crisis económica y de consolidación política, haría obligatoria al mismo tiempo la posición de respeto y entendimiento con las Comunidades Autónomas tras el frustrado intento (1983-84) de crear una ley nacional de servicios sociales. Sin embargo, ya antes (7 de abril de 1982) aparecía la Ley de Integración Social, con servicios sociales específicos para la discapacidad (LISMI).

En el año 1983 se comienzan a construir nueve Centros de Servicios Sociales, diseñados para ofrecer Servicios Sociales básicos y para formar parte de una red de Centros del sistema público de servicios sociales. Los servicios de que disponían los Centros eran: servicio social de información, valoración y orientación; servicio de animación y desarrollo comunitario; servicio de ayuda a domicilio, y servicio de convivencia. Ahora bien, la futura Ley Marco de Servicios Sociales, así como la red básica de Centros, debían ser compatibles con las leyes autonómicas sobre «asistencia social».

En la consulta internacional que se hizo en 1984 con el objeto de preparar el borrador de la futura Ley de Servicios Sociales ya se indicaba la conveniencia de ampliar los servicios sociales. Junto a una política activa de integración social y dinamización de los grupos hasta llegar a la autonomía. Los referentes básicos que se señalan son la familia y la comunidad. Coordenadas que apenas si se tendrán en cuenta por las Comunidades Autónomas en materia de servicios sociales.

Se produjo un avance (1983-84) en la puesta a punto de los servicios sociales: mayor sensibilidad, una nueva concepción (XXIX Congreso del PSOE, en el 84), aumento de presupuestos, de equipamientos y personal téc-

18 Conceptualmente se iba aclarando lo que debían ser los servicios sociales. Faltaba la plasmación concreta. Es significativo que el núm. 64 (1986) de Documentación Social se dedicara íntegramente a Servicios Sociales y que, años más tarde (1991), el núm. 79 llevara por título "Trabajo Social y Servicios Sociales». 
nico, mayor proyección de su presencia en la base, etc. Todo ello para configurar un sistema que garantizara suficientemente los derechos de todos los ciudadanos a los servicios sociales.

La literatura existente (1986) parecía defender con claridad los servicios sociales polivalentes frente a los servicios sociales diferenciales o compartimentados. También se les llamó «primarios» y «especializados». Los servicios sociales de "atención primaria» o "de base» eran locales, estaban próximos al ciudadano, eran polivalentes y debían integrarse en la vida comunitaria. Al ser de ámbito local, implicaban, entre otras cosas, la intervención de los municipios, que, amparados en la Constitución, debían ser agentes de sí mismos. Así lo recoge la Ley Reguladora de Bases de Régimen Local de 2 de abril de 1985, tras haberse derogado la anterior, aprobada por Decreto de 24 de junio de 1955 . Se quería romper con la tradición centralizadora, cuyos efectos en materia de servicios sociales habían sido: estructura burocrática tendente a la especialización y situados al margen de la vida comunitaria. Por contra, los servicios sociales «especializados» parecen exigir mayor coste, desvinculados en cierto modo del ámbito comunitario y más institucionalizados y profesionalizados.

Con la aprobación de las leyes de Acción Social o de Servicios Sociales por las Comunidades Autónomas se consolidan los servicios sociales especializados, mientras que los servicios sociales comunitarios llevan la peor parte. Así es, porque no todas las Comunidades Autónomas harán referencia expresa a los servicios sociales comunitarios. Lo hacen la Comunidad de Madrid (6 de junio de 1984), que divide los servicios sociales en Generales y Especializados; así como la Comunidad murciana (9 de diciembre de 1985) y la Comunidad catalana (17 de diciembre de 1985).

Era necesario entender que al hablar de los servicios sociales generales, básicos, de atención primaria o comunitarios, nos debíamos regir por el marco de la vida comunitaria y en la perspectiva de la descentralización. Sólo así podía entenderse que el lugar de la prestación había de ser normalmente la comunidad. A partir de esa base, los servicios sociales o comunitarios fueron objeto de un convenio administrativo en 1988 entre el Ministerio de Trabajo y Seguridad Social y cada una de las Comunidades Autónomas "para financiar conjuntamente una red de atención de Servicios Sociales Municipales que permita garantizar unas prestaciones básicas a los ciudadanos en situación de necesidad». La intervención en los citados servicios de uno o más profesionales diferentes no tenía por qué modificar la coordinación de dichos servicios, y la atención a grupos diferenciados de población o por sectores no era más que una clasificación formal de los problemas que afectaban a la comunidad. Antaño se les llamó servicios sociales especiales, pero hoy no nos procura rentabilidad alguna semejante denominación.

En los servicios sociales comunitarios se ensayan programas de mayor o menor complejidad en función de la proporción que guardan sus componentes: los sujetos de la comunidad, el número de profesionales y voluntarios, la participación de las asociaciones y entidades sin ánimo de lucro y la infraes- 
tructura técnico-material. Sin embargo, la tendencia existente, con base en el pasado, intenta romper la tendencia de la especialización de los servicios sociales, obteniendo de momento un escaso progreso de los servicios sociales comunitarios.

\subsection{Final de trayecto: el Plan Concertado}

Para finalizar este segundo apartado nos referiremos al Plan Concertado como un logro sin precedentes entre las tres Administraciones (central, autonómica y local) y cuyo propósito consistía en ofrecer unos servicios sociales básicos, generales, comunitarios o de atención primaria. La red de equipamientos quedaría constituida por Centros de Servicios Sociales, Albergues y Centros de Acogida. Y los objetivos a conseguir: información y orientación, ayuda a domicilio, alojamiento y convivencia, y prevención e inserción social.

El Plan Concertado pone en práctica lo que de diferente modo reflejan las diversas leyes autonómicas referidas a los servicios sociales básicos. Sin embargo, no tienen necesariamente por qué coincidir las prestaciones básicas acordadas en el Plan Concertado y las que cada Comunidad Autónoma refleja y pone en uso según su ley. Lo cierto es que por la intervención del Estado se estructura una red nacional de prestaciones básicas de servicios sociales, acordando el Estado y CC.AA. apoyar a los entes locales en el mismo propósito y elevar el bienestar social de los ciudadanos. También es evidente en esta ocasión la intervención del Estado, al mismo tiempo que se pone de manifiesto la intención de ofrecer a todos los ciudadanos unos servicios sociales de bienestar básicos o comunitarios, públicos y gratuitos.

Una red pública de servicios sociales básicos cuyas prestaciones sociales, precisamente por serlo, han de adecuarse a los cambios sociales, económicos, así como al desarrollo de los nuevos sistemas de producción ${ }^{19}$.

Los Convenios-Programa entre el Ministerio de Asuntos Sociales y las Comunidades Autónomas establecieron cuatro compromisos que asumieron las Administraciones firmantes: compromisos de cofinanciación, de gestión, de información y de asistencia técnica. Los compromisos de cofinanciación obligan a la Administración Central a destinar una consignación específica para el Plan en los Presupuestos del Estado; las Comunidades Autónomas se comprometen a aportar una cifra igual o superior a la que en su caso aporte el Ministerio; y las Corporaciones Locales definirán su aportación según las propias circunstancias y lo que determine la Comunidad Autónoma correspondiente. El compromiso de gestión se fundamenta en la obligación de las Corporaciones Locales de prestar servicios sociales, y en la titularidad de los equipamientos, que es propia de la Corporación Local. Los compromisos de información

19 J. Riechmann (1998), Necesitar, desear, vivir. Sobre necesidades, desarrollo humano, crecimiento económico y sustentabilidad, Los Libros de la Catarata, Madrid. 
CUADRO 4

Plan Concertado de 1988

\begin{tabular}{|c|c|c|c|c|}
\hline Objetivos & Aspectos relevantes & Marco jurídico & Prestaciones básicas & Equipamientos \\
\hline $\begin{array}{l}\text { - Garantizar servicios } \\
\text { sociales básicos para } \\
\text { todos. } \\
\text { - Proporcionar servi- } \\
\text { cios de calidad y } \\
\text { adecuados a las ne- } \\
\text { cesidades. } \\
\text { - Cooperarar con las } \\
\text { Corpor a cio n es } \\
\text { Locales en materia } \\
\text { de servicios sociales. }\end{array}$ & $\begin{array}{l}\text { - Voluntad de acuer- } \\
\text { do entre las tres } \\
\text { Administraciones. } \\
\text { — Articulación de un } \\
\text { sistema de finan- } \\
\text { ciación de carácter } \\
\text { finalista. } \\
\text { — Universalidad de } \\
\text { las prestaciones. } \\
\text { - Vías de colabora- } \\
\text { ción, asistencia e } \\
\text { intercambio de in- } \\
\text { formación. } \\
\text { - Cofinancia la Red } \\
\text { Pública Municipal } \\
\text { de servicios socia- } \\
\text { les. }\end{array}$ & $\begin{array}{l}\text { - Constitución española: artí- } \\
\text { culos 41, 139, 148.1.20 y } \\
149.1 .1 . \\
\text { - Ley Reguladora de Bases de } \\
\text { Régimen Local (Ley } 7 / 1985, \\
\text { de } 2 \text { de abril): art. } 25.1 \text { y } \\
25.2 . \mathrm{k} \text {, art. 26.1.c., art. } 10.2 \\
\text { y art. } 57 . \\
\text { - Convenio administrativo } \\
\text { entre las tres Administracio- } \\
\text { nes para articular la coopera- } \\
\text { ción económica técnica y dar } \\
\text { una prestación de servicios } \\
\text { sociales básicos. }\end{array}$ & $\begin{array}{l}\text { - Información y orientación: } \\
\text { para acceder y usar los recur- } \\
\text { sos sociales y prevenir desi- } \\
\text { gualdades en su uso; se dirige } \\
\text { a individuos, grupos e insti- } \\
\text { tuciones sobre los derechos } \\
\text { que les corresponden; aseso- } \\
\text { ramiento sobre problemas } \\
\text { sociales a los demás servicios } \\
\text { sociales existentes. } \\
\text { - Ayuda a domicilio: a indivi- } \\
\text { duos y/o familias en su } \\
\text { domicilio que no pueden } \\
\text { realizar sus actividades habi- } \\
\text { tuales o padecen situaciones } \\
\text { conflictivas psicofamiliares. } \\
\text { - Alojamiento y Convivencia: } \\
\text { es una alternativa para quie- } \\
\text { nes carecen de ambiente } \\
\text { familiar adecuado. } \\
\text { - Prevención e Inserción } \\
\text { Social: atiende a personas y } \\
\text { grupos en situación de riesgo } \\
\text { o marginación, con necesida- } \\
\text { des de sentirse aceptados e } \\
\text { integrados. }\end{array}$ & $\begin{array}{l}\text { - Centros de Servicios Sociales, } \\
\text { Centros de Acogida y Alber- } \\
\text { gues } \\
\text { - Centros de Servicios Sociales: } \\
\text { son de carácter comunitario, } \\
\text { dotados de equipamientos téc- } \\
\text { nicos, incluidas las Unidades } \\
\text { de Trabajo Social, y de los } \\
\text { medios necesarios que dan } \\
\text { soporte a las Prestaciones Bási- } \\
\text { cas. } \\
\text { - Centros de Acogida: estableci- } \\
\text { mientos residenciales no per- } \\
\text { manentes que acogen con } \\
\text { carácter de urgencia a personas } \\
\text { con graves conflictos convi- } \\
\text { venciales o carentes de medio } \\
\text { familiar. } \\
\text { Albergues: equipamientos de } \\
\text { carácter temporal para tran- } \\
\text { seúntes sin medios econó- } \\
\text { micos y otras personas margi- } \\
\text { nadas. }\end{array}$ \\
\hline
\end{tabular}


responden a la necesidad de conocer los resultados de la cconcertación y se materializan en una documentación homogénea, que fue aprobada por la Comisión de Seguimiento para la presentación de proyectos, evaluación anual y memoria financiera, de modo que permitieran el necesario seguimiento del Plan Concertado. El compromiso de asistencia técnica procura un espacio de intercambio de experiencias para su concreción y efectividad, mediante la formación de profesionales y la participación en el desarrollo de instrumentos de recogida de información, como la Ficha Social, que permitan a las tres Administraciones conocer y evaluar los servicios sociales que se prestan a los ciudadanos. Finalmente, la Comisión de Seguimiento del Plan (Directores Generales de las CC.AA. y la Directora General de Acción Social del Ministerio de Asuntos Sociales) tiene como objetivo resolver cuestiones generales que puedan plantearse.

Al cabo de algunos años (1988-1997) existe el consenso entre todas las Comunidades Autónomas sobre un Catálogo de Prestaciones que determine su contenido y límites ${ }^{20}$. El Catálogo de Prestaciones coincide con los objetivos del Plan Concertado mantenidos hasta ahora y que figuran en el cuadro anterior. No obstante, se precisan y amplían algo más los objetivos anteriores a partir de los momentos actuales. Se vuelve a hacer mención de prestaciones como la Información y Orientación, Apoyo a la Unidad Convivencial y Ayuda a Domicilio, Alojamiento Alternativo, Prevención e Inserción y Fomento de la Solidaridad: Cooperación Social.

Si precisamos algo más el Catálogo de Prestaciones diremos que: la Información y Orientación va destinada al conjunto de la población, y que se ofrece desde las unidades de trabajo social y desde los Centros de Servicios Sociales; el Apoyo a la Unidad Convivencial tiene como usuarios a las familias, personas mayores, personas con discapacidad o afectadas por una lesión, enfermedad física o mental, menores, colectivos específicos y cualquier situación de desatención social o familiar que lo requiera, pudiendo prestarles ayuda a domicilio, ayudas técnicas y diversos apoyos desde las citadas unidades de trabajo social y Centros de Servicios Sociales; el Alojamiento Alternativo se destina a las personas imposibilitadas de satisfacer las necesidades básicas, con graves deficiencias de convivencia sociofamiliares y por carecer de un alojamiento digno y estable, a quienes se les ofrece centros de alojamiento estable o temporal (albergues, centros de acogida, viviendas tuteladas, centros residenciales, etc.); la Prevención e Inserción se dirige tanto a toda la población como a un conjunto de personas o diana poblacional con la intención de cambiar su trayectoria vital, para lo cual se dispone tanto de recursos humanos especializados como de medios materiales (servicios de atención domiciliaria, comedores sociales, albergues,

${ }^{20}$ Ministerio de Trabajo y Asuntos Sociales (1998), Catálogo de Prestaciones de Servicios Sociales de Atención Primaria, Secretaría General de Asuntos Sociales, Madrid. Cfr. Ministerio de Trabajo y Asuntos Sociales (1997), El Sistema Público de Servicios Sociales, Subdirección General de Publicaciones, Madrid. 
centros de día infantiles y pre-talleres...), además de entidades sin ánimo de lucro, agrupaciones de voluntariado y grupos informales pertenecientes a la comunidad; y, finalmente, el Fomento de la Solidaridad: Cooperación Social, destinada a potenciar y promover la participación y organización comunitaria, cuenta con equipos profesionales de atención social primaria y especializados, con entidades sin ánimo de lucro, agrupaciones de voluntariado y grupos formales e informales, y con medios materiales (servicios de atención domiciliaria, comedores sociales, albergues, centros de día especializados, infantiles, pre-talleres, residencias, servicios de diagnóstico).

Hemos podido comprobar que la red mencionada de equipamientos del Plan Concertado (Centros de Servicios Sociales, Albergues y Centros de Acogida) se quiere ampliar hasta llegar al conjunto de prestaciones y medios consensuado por todas las Comunidades Autónomas y que acabamos de presentar en este apartado. Es más, si observamos los equipamientos del Plan Concertado, constituyen una red pública universal que trata de salir al paso de quienes viven, por toda una serie de circunstancias personales y sociales, en situaciones críticas. Por eso precisamente, Anthony Giddens responde a la pregunta de si está a favor de mantener servicios sociales universales, o de concentrarlos en los más necesitados, del siguiente modo: "Debe haber algunos servicios universales, porque, de otro modo, los sistemas de bienestar no resultan atractivos a las clases medias y a los profesionales, y los dos ámbitos clave en los que son necesarios son la educación y la sanidad. Pero en otras cuestiones, al darse una regionalización, una concentración de la pobreza, debe haber objetivos concretos para superar esos aspectos de la desigualdad $»^{21}$.

\section{SOBRE CIFRAS Y PRESTACIONES DEL PLAN CONCERTADO}

Partimos de un Plan Concertado que, en definitiva, se hace visible a través de los Ayuntamientos, siendo éstos los que ofrecerán los servicios sociales básicos a sus ciudadanos. Los municipios concertantes son los que en un principio cuentan con un proyecto de Centro de Servicios Sociales. Precisamente en el año 1988, que es cuando comienza el Plan Concertado, serán 2.825 municipios, 35 por 100 del total (8.054) de los existentes, los que se beneficiaron de la colaboración entre el Ministerio de Asuntos Sociales y las Comunidades Autónomas.

\subsection{Primera referencia (1991)}

El Plan Concertado de 1988 comienza su andadura al año siguiente. El Plan abarca, cuatro años más tarde, a 5.982 municipios españoles (79 por 100)

${ }^{21}$ El País, domingo 25 de julio de 1999: «La Tercera Vía es la izquierda del centro». 
con 29.734.825 millones de población (83 por 100), según la Memoria de 1991, año que tomamos como primera referencia. El Plan Concertado estimula los servicios sociales comunitarios existentes y amplía la cobertura, entendiendo que se actúa sobre una estructura que ya funcionaba. Lo cierto es que la cobertura se sitúa en torno al 80 por 100 , lo que no quiere decir que el mismo porcentaje de ciudadanos residentes tengan de hecho a su alcance la red.

Los medios de que dispone el Plan Concertado, según la citada Memoria, ascienden a 29.009.502.335 pesetas, con 744 Centros de Servicios Sociales (96 por 100), 12 albergues (2 por 100) y 21 Centros de Acogida (3 por 100). Un total de 11.017 trabajadores (51 por 100 en plantilla) y, de éstos, 2.665 (50 por 100) son trabajadores sociales y un escaso 5 por 100 son titulados superiores. En definitiva, del total de personal corresponden a 3,7 agentes por cada 10.000 habitantes. También hemos de advertir que no todas las Comunidades Autónomas participaron en el Plan Concertado: el País Vasco nunca participó y Navarra sí lo hizo en 1989. Ambas Comunidades se financiaban a través del sistema de cupo $^{22}$.

\section{TABLA 1}

Aportaciones del Plan Concertado entre 1988-1991

(En millones de pesetas)

\begin{tabular}{lrrrr}
\hline & 1988 & \multicolumn{1}{c}{1989} & \multicolumn{1}{c}{1990} & \multicolumn{1}{c}{1991} \\
\hline Crédito total ............................... & $5.829,9$ & $11.834,1$ & $20.990,5$ & $29.254,5$ \\
Corporaciones Locales ................ & $2.418,4$ & $5.368,4$ & $8.421,6$ & $12.075,6$ \\
Comunidades Autónomas .............. & $1.912,3$ & $3.965,6$ & $7.068,8$ & $9.589,2$ \\
Ministerio de Asuntos Sociales ........ & $1.499,1$ & $2.499,9$ & $5.449,9$ & $7.589,2$ \\
\hline
\end{tabular}

FUENTE: Memoria anual de 1991, p. 129.

Se puede comprobar que en los inicios del Plan Concertado el mayor peso lo soportan las Corporaciones Locales, si tenemos en cuenta que pasan de aportar 2.418,4 millones de pesetas a 12.075,6 en el año 1991. Sin embargo, es evidente también el rápido crecimiento de la aportación del resto de las Administraciones. Ahora bien, los municipios españoles nunca habían contado con recursos y voluntad política en materia de servicios sociales, y ahora era el momento de demostrar la capacidad de poner en funcionamiento un nivel básico de prestaciones de servicios sociales, aunque el presupuesto rondara las 1.000 pesetas per cápita. Se puede decir, entre luces y sombras, que en esta primera fase el acuerdo funcionaba.

${ }^{22}$ Ministerio de Trabajo y Asuntos Sociales (1991), Plan Concertado de Prestaciones Básicas de Servicios Sociales en Corporaciones Locales. Memoria anual de 1991, Madrid, p. 13. 
Los gastos del Plan en un 50 por 100 corresponden al pago de personal. Y un 38 por 100 del total se destina al desarrollo de las prestaciones básicas, fundamentalmente en los 39 Centros de Servicios Sociales. En estos últimos el ratio de gasto ordinario se sitúa entre 250 pesetas y algo más de 1.000 pesetas por habitante/año.

El número de centros de servicios sociales, que es de 744 en 1991, ha descendido respecto del año anterior (764 centros en 1990), si bien es cierto que modalidades de equipamientos más complejas habían aumentado. Sin embargo, los centros de acogida (menores y mujeres) apenas si han aumentado porque son 21 centros en 1991 y en 1988 figuran 18 centros. Lo mismo diríamos de los 12 albergues, que son 10 en el año de inicio del Plan. El conjunto de los equipamientos es posible que fuera escaso para las 17 Comunidades Autónomas.

Según las funciones desempeñadas, el 40 por 100 de los trabajadores se dedica a la ayuda a domicilio y el 25 por 100 a la prestación de los servicios de información y orientación.

\section{TABLA 2}

Funciones del Plan Concertado (1991)

\begin{tabular}{|c|c|c|c|c|}
\hline \multirow[b]{2}{*}{ Prestaciones } & \multirow[b]{2}{*}{ Plantilla } & \multirow[b]{2}{*}{ Prestaciones } & \multicolumn{2}{|c|}{ Total } \\
\hline & & & $N$ & $\%$ \\
\hline Información y Orientación . ............. & 2.548 & 171 & 2.719 & 25 \\
\hline Ayuda a Domicilio .......................... & 591 & 3.862 & 4.453 & 40 \\
\hline Alojamiento Alternativo ..................... & 89 & 37 & 126 & 1 \\
\hline Prevención e Inserción ...................... & 433 & 701 & 1.134 & 10 \\
\hline 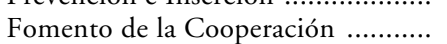 & 43 & 59 & 102 & 1 \\
\hline 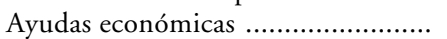 & 1.284 & 115 & 1.399 & 13 \\
\hline 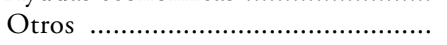 & 733 & 351 & 1.084 & 10 \\
\hline 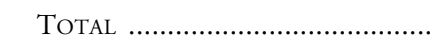 & 5.721 & 5.296 & 11.017 & 100 \\
\hline
\end{tabular}

FUENTE: Memoria anual de 1991, p. 60.

Parece quedar claro que la «Información y Orientación» constituye la base indiscutible de los Centros, mientras que la ayuda a domicilio es la manifestación externa más clara de las prestaciones. Por número de usuarios, el 64 por 100 demandan información y orientación, mientras que en segundo lugar el 30 por 100 de usuarios lo son de prevención e inserción. Los datos sobre «Alojamiento Alternativo" se corresponden con las cifras ya comentadas sobre "centros de acogida» $\mathrm{y}$ «albergues». Y, finalmente, el resto de cifras se puede considerar importante por ser una muestra de adaptación a las exigencias locales de la población.

Una vez expuestas las cifras principales del Plan Concertado (1988-1991) 
en este primer período, se pueden sopesar algunos de los logros alcanzados en servicios sociales comunitarios, según los datos oficiales suministrados por el Ministerio. Resulta obvio, además de la inversión prioritaria de las Corporaciones Locales, que el gasto más importante del Plan lo absorbe el pago de personal, y que en materia de prestaciones es la ayuda a domicilio (SAD) la que alcanza el mayor porcentaje (40 por 100) de las mismas, seguida de Información y Orientación. También es importante recordar que el Plan Concertado es un éxito de acuerdo entre las tres Administraciones.

En el año 1993 podemos hablar de consolidación del Plan Concertado si tenemos presente que abarcaba al 80 por 100 de los municipios de su ámbito de aplicación. Claro que, como ya se dijo, debe excluirse el País Vasco y Navarra a partir de 1991, quedando contemplados por el Plan 7.553 municipios. Lo cierto es que se había producido un importante progreso porque la fecha para conseguir la cobertura total de los municipios españoles era el año 1995.

En el año 1994, no todas las Comunidades Autónomas reflejaban en sus presupuestos «el peso debido» a los servicios sociales de base. Comparando en aquel año el gasto de servicios sociales en cuatro Comunidades Autónomas como Cataluña, Andalucía (con importantes cifras), Madrid y Navarra (centro y periferia con cifras notablemente más modestas) obteníamos unas claras prioridades que resumimos a continuación, por orden de importancia ${ }^{23}$ :

- Cataluña se decanta por servicios sociales para:

- Disminuidos (15.229 millones de pesetas).

- Personas mayores (16.334).

- Pensiones asistenciales (6.729).

- Atención primaria (4.221).

- Subvenciones a entidades sin ánimo de lucro (se contemplan dentro de los apartados anteriores y de otros; difíciles de precisar) ${ }^{24}$.

- CAM (Madrid) hace el reparto básicamente entre:

— Prestaciones económicas/red básica de servicios sociales (18.855.835.052 ptas. y 20.829.604.938 ptas.).

- Personas mayores/infancia (por sectores), así como los convenios/subvenciones con entidades sin ánimo de lucro, tienen menor importancia ${ }^{25}$.

23 Antonio Gutiérrez Resa (1996), "Usía y Manía» de los Servicios Sociales en España, ponencia presentada en el Primer Congreso Nacional de Escuelas Universitarias de Trabajo Social: "Política Social y Bienestar Social», celebrado en Valencia los días 8-10 de abril de 1996. Cfr. Antonio Gutiérrez Resa (1997), Acción Social No Gubernamental, Tirant Lo Blanch, Valencia, pp. 138-140. Allí se exponen los datos completos sobre gasto en servicios sociales en las Comunidades Autónomas de Cataluña, Madrid, Andalucía y Navarra.

24 El presupuesto de ICASS para Servicios en 1994 era de 44.003 millones de pesetas.

25 El Presupuesto de la CAM para 1994 era de 44.000 millones de pesetas. 
- Andalucía hace la distribución básicamente entre:

- Pensiones asistenciales y servicios sociales (37.809.842 ptas. y 32.818.663 ptas.).

— Menores y acción social (7.115.647 ptas. y 6.105 .703 ptas.).

- La gestión tiende a ser privada en algunos sectores (residencias de día y jóvenes), aunque es mayor la gestión pública ${ }^{26}$.

- Navarra $^{27}$ se decanta básicamente por:

- La tercera edad/minusválidos (el 42,2 y 27,1 por 100 de un presupuesto en el año 93 de 13.119,4 millones de pesetas).

- Servicios sociales de base (el 3,8 por 100 del presupuesto).

- Crece la iniciativa privada mercantil en residencias para la tercera edad.

A tenor de estos último datos complementarios referidos al año 1994 haremos unas últimas observaciones. El Plan Concertado estaba siendo el exponente acordado para ofertar unos servicios sociales de base mínimos en todas las Comunidades Autónomas. No obstante, las prioridades reflejadas de las cuatro Comunidades Autónomas citadas quedaban de manifiesto aunque mantuvieran la red de servicios sociales básicos. Queremos decir que aunque los servicios sociales de base pudieran contemplarse como prioritarios, precisamente por ser básicos, lo comprobado es que son otras las preferencias de Cataluña, Madrid, Andalucía y Navarra en el reparto de presupuestos de servicios sociales y acción social. También por entonces se aprecia una clara búsqueda de la colaboración del voluntariado, se inician experiencias de gestión privada, e intentan rebasar la clasificación lucro y no-lucro de los servicios, utilizando los criterios de participación-ahorro y calidad-proximidad-conocimiento.

\subsection{Segunda referencia (1995)}

Entre el año 1994-1995 se realizaba un análisis del Plan Concertado que tomamos como segunda referencia y cuyas constantes relatamos a continuación $^{28}$. Exponemos los aspectos más destacados que abarcan cuestiones clave para la orientación y buen funcionamiento del Plan de Prestaciones Básicas de Servicios Sociales:

${ }^{26}$ La Comunidad Autónoma de Andalucía disponía en 1994 de un crédito definitivo en acción social y servicios sociales de 96.769 .028 pesetas.

${ }_{27}$ Quedan excluidas Navarra y País Vasco del Plan Concertado, en atención al especial régimen económico y financiero de ambas Comunidades.

${ }^{28}$ Hemos tomado como base los datos obtenidos de los Anuarios del Plan Concertado y la Memoria del Primer Congreso Nacional sobre el Sistema Público de Servicios Sociales, celebrado en A Coruña en el año 1994. 
- Nadie duda de que son los Ayuntamientos los conocedores de las necesidades y donde deben centrarse las prestaciones de los servicios sociales.

- Ha faltado planificación estratégica en el ámbito de los servicios sociales municipales.

- No existe conciencia social sobre el derecho a disfrutar de prestaciones sociales que oferta la red básica de servicios sociales cuando se padecen determinadas situaciones sociales.

- No existen evaluaciones sobre programas y objetivos, así como el sistema actual de información, sino recuentos de algunas actividades, usuarios y recursos del Plan Concertado. Tampoco se ha evaluado la satisfacción de los usuarios ni la mejora objetiva de la calidad de vida de los mismos (indicadores comunes).

- Si las plantillas han crecido, debemos tender a conocer también el crecimiento adecuado de los usuarios, especificando las prestaciones por prevención, promoción e integración comunitaria que reciben.

- Los centros de servicios sociales deben contar con recursos suficientes, tanto presupuestarios como técnicos y humanos. No obstante, del número total de trabajadores, algo menos del 50 por 100 de los mismos trabajan en el desarrollo de programas (1988-1993).

- Los centros de servicios sociales han de analizar el consumo y servicio burocrático que hacen, coordinando y descentralizando tareas-funciones. Aumentar el número de los mismos, así como los componentes de los equipos. No es posible resolver problemas complejos con unidades simples.

- Es conveniente aclarar el papel que debe desempeñar la solidaridad en sus diferentes niveles en función de los servicios sociales. No es un capital a disposición del Plan Concertado, sino el valor añadido de que dispone la sociedad civil.

- Los criterios de distribución de la financiación pueden revisarse y ponerse a punto buscando el consenso (actualización de los «mapas» en las Comunidades Autónomas).

- Es un hecho la dificultad que ha supuesto la implantación de la ficha social. Sin embargo, afrontar otros retos con los medios informáticos de hoy perfeccionaría el seguimiento y análisis del Plan Concertado.

- La formación de los profesionales del Plan Concertado es fundamental para que aquél evolucione técnica y sociológicamente. De este modo se sale al paso de la llamada polivalencia y rutina profesional. La definición de funciones debe alcanzar mayores niveles de esfuerzo si deseamos una red con identidad y capaz de alcanzar lo que le pidan los usuarios.

- No se conoce el número de usuarios derivados de otros servicios como los educativos, sanitarios y laborales. En esa línea de información tenemos la clave de la demanda, así como de la evolución y cambio del Plan Concertado. 
- La indefinición de algunas prestaciones como la prevención e inserción resta identidad, eficacia y eficiencia al Plan Concertado. Por eso se decía que el Plan Concertado carecía de una clara definición conceptual y operativa de las prestaciones.

- La flexibilidad o incremento de prestaciones especializadas pone de manifiesto la necesidad de adaptar el Plan Concertado y de redefinirlo en función de servicios especializados de base o básicos.

- Es importante saber de la dotación de los centros de servicios sociales: si sus equipamientos son suficientes, adecuados y de la calidad necesaria. Los ratios poblaciones deben ajustarse.

- Se desconoce si las transferencias trimestrales a los Ayuntamientos han agilizado el proceso o complican aún más el sistema.

- Falta información para poder establecer la correlación de datos. De este modo se podrían presentar conclusiones que no se ofrecen a simple vista y que serían de gran utilidad para desarrollar estándares de los servicios sociales de base.

No cabe duda de que la autocrítica que se hacía el Plan Concertado en el año 1994-95 era valiente y muy detallada. Se había sobrepasado el ecuador de los siete años de andadura que ahora analizamos, y no era de extrañar que aparecieran problemas técnicos, dificultades de coordinación y una mayor demanda de recursos. Aun con todo, el Plan Concertado seguía manteniendo una importante inversión, mantenía una casi total cobertura y ofrecía una serie de prestaciones básicas que, naturalmente, podían aumentarse.

El Plan Concertado seguía centrando su actuación en los Ayuntamientos, aunque éstos adolecieran de planificación estratégica y los potenciales usuarios no tuvieran conciencia del derecho a disfrutar de las prestaciones sociales. También se echaba en falta información para poder correlacionar datos sobre los efectos positivos o no de las transferencias trimestrales a los Ayuntamientos, sobre la dotación de los centros de servicios sociales y sobre el número de usuarios provenientes de otros servicios.

Aunque el Plan en términos generales se había consolidado tras siete años de andadura, no disponía de evaluaciones por objetivos ni se había evaluado la satisfacción de los usuarios; había recuentos de algunas actividades, y eso que había costado implantar la ficha social como base del seguimiento y análisis del Plan Concertado. Existía preocupación porque los centros controlaran el posible aumento de burocracia, porque aumentaran las plantillas, la formación de los profesionales y se analizara el crecimiento adecuado de usuarios. Y, finalmente, la autocrítica alcanzaba a la supuesta indefinición de algunas prestaciones, la flexibilidad e incremento de otras, el papel de la solidaridad y los criterios de distribución de la financiación según los nuevos «mapas» en las Comunidades Autónomas. 


\section{ONCE AÑOS CON EL MISMO VEHÍCULO (LOGROS MÁS SIGNIFICATIVOS)}

Finalizado el año 2000 se cumplían más de diez años desde que se iniciara el Plan Concertado ${ }^{29}$. Las aportaciones económicas de los Entes Locales, Comunidades Autónomas y Ministerio reflejan algunos cambios y se producen algunas variaciones en las prestaciones básicas. No obstante, son más de diez años de andadura cuya acumulación de datos nos va a servir para analizar y presentar las últimas pautas encontradas.

\subsection{Aportaciones económicas del Plan Concertado}

Las aportaciones económicas al Plan Concertado provienen de los Entes Locales, las Comunidades Autónomas y el Ministerio, y son a lo largo de los años las que mostramos a continuación.

\section{TABLA 3}

Aportaciones económicas al Plan Concertado (1988-1998)

\begin{tabular}{|c|c|c|c|c|c|}
\hline & Años & CC.LL. & CC.AA. & MTAS & Total \\
\hline 988 & & 2.418 .844 .000 & 1.912 .376 .000 & 1.499 .100 .000 & 5.829 .960 .000 \\
\hline 1989 & & 5.487 & 3.96 & 2.499 . & 1.953 .066 .000 \\
\hline 1990 & & 8.722 .287 .310 & 7.068 .8 & 5.499 .997 .000 & 21.291 .142 .585 \\
\hline 1991 & & 12.910 .280 .226 & 9.689 .673 .498 & 7.589 .222 .740 & 30.189 .176 .464 \\
\hline 1992 & & 14.831 .035 .752 & 10.822 .722 .502 & 8.200 .0 & 33.853 .758 .254 \\
\hline 1993 & & 21.521 .6 & 11.410 . & 8.613 & 41.545 .436 .793 \\
\hline 1994 & & 25.049 .866 .616 & 13.074 . & 0.000 & 46.737 .625 .633 \\
\hline 1995 & & 36.860 .956 .695 & 13.675 .189 .304 & 9.999 .498 .201 & 60.535 .644 .200 \\
\hline 1996 & & 37.825 .016 .981 & 15.496 .527 .547 & 10.513 .751 .259 & 63.835 .295 .787 \\
\hline 1997 & & 37.563 .865 .788 & 16.530 .511 .633 & 11.510 .000 .000 & 65.604 .377 .421 \\
\hline 1998 & & 38.755 .037 .994 & 18.826 .1 & 12.000 .000 .000 & 69.581 .181 .611 \\
\hline 1999 & ............. & 31.243 .268 .151 & 19.874 .260 .842 & 12.776 .200 .000 & $64.518 .546 .046^{*}$ \\
\hline
\end{tabular}

* Se trata de la contribución prevista por las Administraciones concertantes.

Fuente: Anuarios del Plan Concertado ${ }^{30}$.

29 En el año 1998 se celebraban las VII Jornadas Nacionales de Servicios Sociales en el Medio Rural, celebradas en Jaca en el mes de octubre y que hacen expresa y amplia referencia al Plan Concertado. Inmediatamente después tenía lugar en Guadix (Granada) un Curso sobre Evaluación del Plan Concertado de Servicios Sociales, diez años después (10-21 de noviembre de 1998).

${ }^{30}$ En diciembre de 1999 no se disponía todavía del Anuario del Plan Concertado correspondiente al año 1999. La última Memoria consultada ha sido la correspondiente a 1998-1999. En el total de las aportaciones se incorporan los remanentes, como puede verse en 1999. En este año los remanentes ascienden a 624.817 .053 pesetas. 
Destacamos del cuadro de aportaciones económicas el mayor y más constante esfuerzo económico que vienen haciendo los entes locales (55 por 100 en 1998). Probablemente, se dice, están tocando techo. Son quienes más aportan, advirtiéndose un fuerte incremento en el año 1995 y un claro estancamiento, por el contrario, en 1997. Si observamos la trayectoria de las aportaciones de las Comunidades Autónomas, el aumento ha sido progresivamente moderado, estancándose en los años 1994-95 y volviéndose a recuperar en 1996 y 1997. En el caso del Ministerio se puede comprobar que, aunque el aumento también ha sido progresivamente moderado, se estanca en los años 1992, 1993 y 1994, recuperándose en 1995. Tampoco son iguales las aportaciones de las Corporaciones Locales (Islas Baleares el 74 por 100, Cataluña el 70 por 100 y Extrenadura el 23 por 100) y de las Comunidades Autónomas (Extremadura, 54 por 100; Islas Baleares, 14 por 100, y Cataluña, 15 por 100). Añadiremos que existen cantidades importantes que se gestionan en el marco del Plan pero que son externas a lo aportado por la Administración: las cantidades pueden proceder de Diputaciones Provinciales, Consells o Cabildos Insulares, de Consejerías de las Comunidades Autónomas, de la Administración General del Estado o de los propios usuarios.

$\mathrm{Si}$ nos referimos a los equipamientos que se presentan en el cuadro del apartado siguiente, se puede ver la inclusión de Centros de Acogida para Menores, Mujeres y Polivalentes en el año 1997.

\subsection{Equipamientos del Plan Concertado}

En el cuadro que presentamos se expone, de modo resumido, el conjunto de las prestaciones básicas del Plan Concertado. 
TABLA 4

Equipamientos del Plan Concertado. Evolución 1988-1998

\begin{tabular}{|c|c|c|c|c|c|c|c|c|c|c|c|c|c|}
\hline & 1988 & 1989 & 1990 & 1991 & $88-91$ & 1992 & 1993 & 1994 & 1995 & 1966 & 1997 & 1998 & 1999 \\
\hline Total Proyectos & 417 & 601 & 801 & 777 & $86 \%$ & 851 & 815 & 826 & 964 & 987 & 1.024 & 1.144 & 1.154 \\
\hline 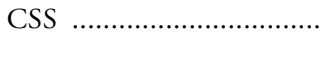 & $\begin{array}{l}389 \\
93,3 \%\end{array}$ & $\begin{array}{l}567 \\
94,3 \%\end{array}$ & $\begin{array}{l}764 \\
95,4 \%\end{array}$ & $\begin{array}{l}744 \\
95,7 \%\end{array}$ & 91 & 813 & 780 & $\begin{array}{l}792 \\
795\end{array}$ & 926 & 949 & $\begin{array}{l}986 \\
96 \%\end{array}$ & $\begin{array}{l}1.107 \\
97 \%\end{array}$ & $\begin{array}{l}1.118 \\
97 \%\end{array}$ \\
\hline Equipamiento Integral ...... & 2 & 9 & 28 & 51 & & $\begin{array}{l}122 \\
129\end{array}$ & 149 & $\begin{array}{l}204 \\
175\end{array}$ & 208 & 231 & $\begin{array}{l}306 \\
\text { Comar. }\end{array}$ & $\begin{array}{l}314 \\
\text { Comar. }\end{array}$ & \\
\hline Estructura Intermedia ....... & 42 & 202 & 393 & 466 & & $\begin{array}{l}411 \\
470\end{array}$ & 470 & $\begin{array}{l}445 \\
499\end{array}$ & 495 & 535 & $\begin{array}{l}570 \\
\text { Munic. }\end{array}$ & $\begin{array}{l}667 \\
\text { Munic. }\end{array}$ & \\
\hline 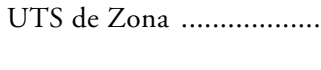 & 345 & 356 & 343 & 227 & & $\begin{array}{l}280 \\
214\end{array}$ & 161 & $\begin{array}{l}143 \\
121\end{array}$ & 223 & 176 & $\begin{array}{l}38 \text { Barrio } \\
72 \text { Manc }\end{array}$ & $\begin{array}{l}38 \text { Barric } \\
88 \text { Man }\end{array}$ & \\
\hline 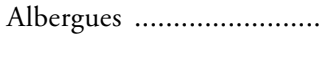 & 10 & 15 & 13 & 12 & $20 \%$ & 17 & 16 & $\begin{array}{l}17 \\
16\end{array}$ & 18 & 18 & 17 & 17 & 15 \\
\hline 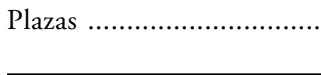 & 262 & 326 & 532 & 486 & & 653 & 560 & $\begin{array}{l}693 \\
583 \\
\end{array}$ & 702 & $\begin{array}{l}686 \\
698 \\
\end{array}$ & 701 & 574 & \\
\hline Centros de Acogida ........... & 18 & 19 & 24 & 21 & & 21 & 19 & $\begin{array}{l}14 \\
15\end{array}$ & 20 & 20 & $\begin{array}{l}21: \\
\text { Mujer } 9 \\
\text { Menor } 4 \\
\text { Poliv. } 8\end{array}$ & $\begin{array}{l}21: \\
\text { Mujer } 9 \\
\text { Menor } 3 \\
\text { Poliv. } 9\end{array}$ & $\begin{array}{l}21: \\
\text { Mujer } 9 \\
\text { Menor } 3 \\
\text { Poliv. } 8\end{array}$ \\
\hline 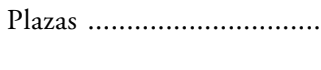 & 304 & 276 & 439 & 420 & & 527 & 379 & $\begin{array}{l}257 \\
323\end{array}$ & 417 & $\begin{array}{l}423 \\
439\end{array}$ & 529 & 522 & \\
\hline
\end{tabular}

Fuente: Anuarios del Plan Concertado ${ }^{31}$.

${ }^{31}$ Aquellas cifras que están en cursiva reflejan la no coincidencia de datos por el mismo concepto en el avance del Anuario del año anterior y en el Anuario del año correspondiente. 
Como se puede comprobar por la tabla, la estructura del Plan Concertado se basa en la oferta de servicios básicos que los prestan centros de tres niveles o categorías: centros de servicios sociales, albergues y centros de acogida. En el 97 se prescinde de la clasificación por tipologías que se venía manteniendo de los Centros de Servicios Sociales, y se habla de Comarcas, Municipios, Barrios y Mancomunidades, teniendo presente que se evoluciona hacia una implantación municipal de los servicios sociales. Los albergues y centros de acogida se mantienen en una situación estable. Y desde 1999 se incorporan al marco de cofinanciación del Plan Concertado las Ciudades Autónomas de Ceuta y Meli$11 a^{32}$.

Los Centros de Servicios Sociales constituyen equipamientos de carácter comunitario, dotados de los equipos técnicos, incluidas las unidades básicas de trabajo social o denominación similar, y los medios necesarios que dan soporte a las prestaciones básicas. Suelen contar con una o varias sedes principales (1.163), delegaciones o sedes descentralizadas (3.415).

Los albergues van destinados a transeúntes sin medios económicos y otras personas marginadas, procurando su inserción personal y social.

Los Centros de Acogida atienden, en medida de urgencia, a personas en situación de graves conflictos convivenciales o carentes de medio familiar adecuado, intentando lograr la normalización de la convivencia. Se distinguen tres tipos: menores (de 0-15 años), mujeres y de carácter polivalente.

\subsection{Análisis y valoración de los datos del Plan Concertado}

Ateniéndonos a los datos oficiales suministrados por los Anuarios del Plan Concertado, podemos ofrecer las siguientes observaciones al cabo de algo más de una década ${ }^{33}$ :

- La cobertura del Plan Concertado alcanza a 6.507 municipios (86 por 100 de los municipios, según la Memoria de 1998-99) y al 97 por 100 de la cobertura poblacional de los municipios (35.924.837 habitantes, según la Memoria de 1998-99), con un promedio de 6 municipios y 33.233 habitantes por proyecto de Centro de Servicios Sociales. Ahora bien, el reflejo más real de la capacidad de atención a los ciudadanos son las Unidades de Trabajo Social, que atienden a 11.138 habitantes por unidad. Los municipios son precisamente los que aglutinan el 60 por 100 de los proyectos de actuación, mientras que

32 El Consejo de Ministros, en su reunión de 18 de junio de 1999, acordó la aprobación de un crédito por importe de 76,2 millones de pesetas para la financiación de proyectos en las Ciudades Autónomas de Ceuta y Melilla, cuyos Convenios de Colaboración se habían firmado en el mes de diciembre.

${ }_{33}$ Incluimos algunas de las conclusiones expuestas en las ya mencionadas VII Jornadas Nacionales de Servicios Sociales en el Medio Rural, celebradas en Jaca en octubre de 1998. 
los proyectos comarcales, mancomunados y de barrio alcanzan el 28, 8 y 4 por 100, respectivamente (según la Memoria de 1998-99). Los Centros de Servicios Sociales cuentan con 1.329 sedes principales y 2.199 descentralizadas ${ }^{34}$.

Se puede apreciar que la cobertura de municipios ha subido pero no alcanza el cien por cien, porcentaje que lo consiguen ocho Comunidades Autónomas. Sin embargo, Castilla-La Mancha, por ejemplo, atiende a 75 municipios de un total de 915 , lo que supone el 8 por 100. Igualmente comprobamos el escaso avance de los ratios de entre 8.000 y 13.000 habitantes/UTS, y eso sin tener en cuenta las diferencias existentes entre Comunidades Autónomas (28.536 hab./UTS en Madrid y 2.647 hab./UTS en Extremadura). También el promedio por proyecto tanto de municipios como de población es patente: de 1 a 5 municipios por proyecto (Andalucía, Asturias, etc.) y superiores a 69 municipios por proyecto (Castilla y León con 80 municipios y La Rioja con 69 municipios/proyecto); respecto al número de habitantes: de -13.000 a 20.000 hab./proyecto CSS (Aragón, Canarias, etc.) y superiores a 70.000 hab./proyecto CSS (Castilla y León, Cataluña, Madrid y La Rioja).

- El gasto por habitante asciende a 2.501-3.000 pesetas/hab. en CastillaLa Mancha y Castilla y León, mientras que Cantabria y Madrid se sitúan entre 1.000 y 1.500 pesetas/hab. (Memoria 98-99), destinándose el 42 por 100 del mismo a personal de plantilla, el 5 por 100 a mantenimiento y el 51 por 100 a desarrollo de prestaciones, mientras que el 2 por 100 restante son inversiones (Memoria 98-99). Lo previsto para 1998 es que el gasto por habitante ascendería a 1.644 pesetas.

También en este apartado comprobamos las diferencias de gasto por habitante según Comunidades Autómomas, así como las diferencias de gasto de personal de plantilla (4 por 100 en Cantabria, y La Rioja y la Comunidad Valenciana no llegan al 25 por 100 de su presupuesto), compensado, salvo en La Rioja, por el mayor gasto en inversiones. Castilla-La Mancha dobla el promedio general de mantenimiento (2 por 100), no siendo apenas perceptible en La Rioja, mientras que esta última Comunidad acentúa las inversiones, y en Galicia es el 13 por 100 del presupuesto. Según la tabla siguiente, se puede apreciar que en general las inversiones, con el 51 por 100 , y personal, con el 42 por 100 , concentran el gasto de los equipamientos.

34 La Mayor parte de los equipamientos comunitarios cuenta con una o varias sedes principales (infraestructuras mejor dotadas como local independiente), así como delegaciones o sedes descentralizadas que, a menudo, coinciden con dependencias donde se ubican las Unidades de Trabajo Social. En todas las Comunidades Autónomas, Salvo La Rioja, el número de sedes principales coincide o supera el número de proyectos presentados como Centros de Servicios Sociales. 


\section{TABLA 5}

Gasto de equipamientos

\begin{tabular}{|c|c|c|c|c|c|c|c|c|}
\hline & \multicolumn{2}{|c|}{ Centros de Servicios Sociales } & \multicolumn{2}{|c|}{ Albergues } & \multicolumn{2}{|c|}{ Centros de Acogida } & \multicolumn{2}{|l|}{ Total } \\
\hline & Gastos & $\%$ & Gastos & $\%$ & Gastos & $\%$ & Gastos & $\%$ \\
\hline …….................. & 28.375 .386 .584 & 41 & 414.897 .856 & 58 & 517.349 .127 & 73 & 29.307 .633 .567 & 42 \\
\hline Mantenimiento ....................... & 3.088 .652 .967 & 5 & 204.990 .784 & 28 & 156.567 .486 & 22 & 3.450 .211 .237 & 5 \\
\hline Prestaciones & 35.368 .873 .217 & 52 & 87.684 .359 & 12 & 25.935 .794 & 4 & 35.482 .493 .370 & 51 \\
\hline 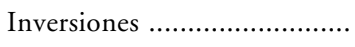 & 1.635 .014 .434 & 2 & 15.512 .321 & 2 & 3.548 .068 & 1 & 1.654 .074 .823 & 2 \\
\hline TOTAL ………………....... & 68.467.927.202 & 100 & 723.085 .320 & 100 & 703.400 .475 & 100 & 69.894 .412 .997 & 100 \\
\hline
\end{tabular}

Fuente: Memoria del Plan Concertado 1998-99. 


\section{TABLA 6}

Desglose de gastos por porcentajes en las CC.AA. del Plan Concertado

\begin{tabular}{|c|c|c|c|c|c|}
\hline CC.AA. & $\begin{array}{c}\text { Crédito } \\
\text { total }\end{array}$ & $\begin{array}{l}\text { Prestaciones } \\
\text { (\%) }\end{array}$ & $\begin{array}{c}\text { Personal } \\
\text { (\%) }\end{array}$ & $\begin{array}{c}\text { Manteni- } \\
\text { miento } \\
(\%)\end{array}$ & $\begin{array}{c}\text { Inversión } \\
(\%)\end{array}$ \\
\hline Andalucía & 16.377 .962 .657 & 47,76 & 43,90 & 5,52 & 2,82 \\
\hline 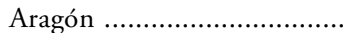 & 1.994 .196 .606 & 49,72 & 46,03 & 4,26 & $\ldots$ \\
\hline  & 2.660 .324 .614 & 61,62 & 32,52 & 4,31 & 0,28 \\
\hline Baleares $\ldots \ldots \ldots \ldots \ldots \ldots \ldots$ & 2.004 .906 .701 & 41,74 & 54,78 & 2,45 & 1,03 \\
\hline 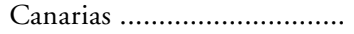 & 3.700 .975 .103 & 51,45 & 43,97 & 4,58 & 0,00 \\
\hline Cantabria ................................ & 771.617 .856 & 93,49 & 3,62 & 2,88 & $\ldots$ \\
\hline Castilla-La Mancha ............ & 3.296 .328 .834 & 42,15 & 48,37 & 9,48 & $\ldots$ \\
\hline Castilla y León .................... & 6.623 .503 .400 & 58,84 & 36,94 & 1,79 & 2,43 \\
\hline 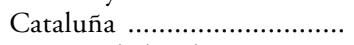 & 11.937 .203 .212 & 33,08 & 59,09 & 7,79 & 0,03 \\
\hline Comunidad Valenciana ...... & 5.541 .666 .977 & 74,46 & 22,54 & 3,00 & $\ldots$ \\
\hline Extremadura ......................... & 1.835 .524 .028 & 61,45 & 33,55 & 4,99 & $\ldots$ \\
\hline 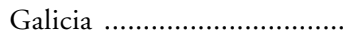 & 5.047 .856 .670 & 41,05 & 41,47 & 4,54 & 12,94 \\
\hline 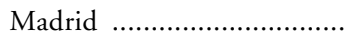 & 5.746 .258 .055 & 65,05 & 27,87 & 2,81 & 4,27 \\
\hline 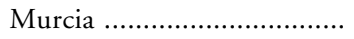 & 2.515 .463 .729 & 52,26 & 43,99 & 3,75 & $\ldots$ \\
\hline 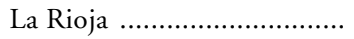 & 465.075 .124 & 51,58 & 20,35 & 0,61 & 27,46 \\
\hline
\end{tabular}

Fuente: Memoria del Plan Concertado 1998-99.

- Los trabajadores pagados por el Plan Concertado son 20.514 (Memoria de 1998-99), de los que 8.674 (42 por 100) constituyen la plantilla (60 por 100 con titulación de Grado Medio y 9 por 100 de Grado Superior) y 11.840 (58 por 100) están contratados con cargo a las prestaciones. Hay un claro predominio de los Trabajadores Sociales en las plantillas (42 por 100 del total de la plantilla) y de los Auxiliares de Hogar o Trabajadores Familiares (75 por 100 del número de trabajadores en prestaciones) entre los que son contratados con cargo a las prestaciones (sobre todo Apoyo a la Unidad Convivencial y Ayuda a Domicilio).

Deberemos añadir que a cada trabajador del Plan Concertado le corresponde atender a una población que, según la Comunidad Autónoma, varía de entre 500 a 1.000 hab./trabajador (Castilla-La Mancha, Galicia y Extremadura) a 4.001-4.500 hab./trabajador (Madrid); mientras que el 64,51 por 100 cumple funciones en plantilla y el 77,24 por 100 en prestaciones. Sobre la dedicación de los trabajadores, el 49 por 100 dedica menos de 35 horas y el 22 por 100 entre 35 y 37,4 horas semanales. El coste salarial por trabajador oscila entre 2 y 3 millones en Islas Baleares, Cantabria y Comunidad Valenciana, y entre 3 y 4 millones en el resto; los trabajadores que menos cobran son los Auxiliares de Hogar, que no superan el medio millón en Galicia y algo más de 800.000 pesetas en La Rioja. Y la relación laboral con la Administración es de contrato fijo laboral para más del 61 por 100 del personal de plan- 
tilla, si bien existen diferencias entre las Comunidades Autónomas. En el cómputo global, existen 656 trabajadores fijos más en 1998 y un incremento de 1.413 puestos de trabajo.

- Los usuarios/servicios del Plan en 1998 ascienden a un total de 2.451.997 personas. Son usuarios que recibieron al menos algún servicio de información de servicios sociales o de otros recursos del sistema: en total, 3.745.271 actuaciones, que arroja un promedio de 1,7 actuaciones por usuario (excluyendo Cataluña, que no aporta información alguna). Las prestaciones hechas a las 2.451 .997 personas atendidas se concentran por sectores en la Familia (37 por 100) y en el sector de las Personas Mayores (21 por 100), y el número de usuarios atendidos oscila bastante según las Comunidades Autónomas (Andalucía con el 17,25 por 100, Cataluña con el 13,04 por 100 y Galicia con el 13,54 por 100 de usuarios de la Comunidad sobre el total). Y el ratio de gasto varía entre 500 pesetas/usuario en Baleares, Canarias y Murcia y las 1.000 pesetas/usuario de La Rioja o Cantabria.

El Apoyo a la Unidad Convivencial y Ayuda a Domicilio es reducido ya que estamos hablando de 203.414 usuarios (12,09 por 100 en Andalucía, 19,86 por 100 en Castilla y León y 12,59 por 100 en Cataluña), que se concentra por sectores en Familia (21,09 por 100) y en Mayores (49,09 por 100) y que ha alcanzado las 577.482 actuaciones, con predominio de las de Ayuda a Domicilio. El promedio de gasto varía entre las 23.392 pesetas/usuario de La Rioja y el más alto en Cantabria con 239.420 pesetas/usuario. Sí que añadiremos en lo que se refiere a la gestión que destaca la concertada en Andalucía (33 por 100), C. Valenciana (18 por 100), Galicia (13 por 100) y Castilla-La Mancha (10 por 100); y la gestión de contrato con empresa lucrativa en Andalucía (31 por 100) y Canarias (12 por 100).

El Alojamiento Alternativo se ha concedido a 97.508 personas (38 por 100 sin Hogar y 27 por 100 Familia), habiéndose realizado 103.268 actuaciones (además de las realizadas en Cataluña, cuyo número se desconoce), lo que supone un ratio de poco más de una actuación por usuario. El coste, salvo Cantabria (650.000 pesetas/usuario), varía entre las 10.000 pesetas/usuario (Aragón, Baleares, etc.) y las 50.000-60.000 pesetas/usuario en Canarias y Madrid.

La Prevención e Inserción Social alcanza a 1.151 .013 usuarios, una cuarta parte de los cuales pertenecía a Personas Mayores y un 22 por 100 a Infancia; y Familia, Mujer y Juventud, con el 10 por 100. Se han alcanzado 643.593 actuaciones (sin contar Cataluña), de las que la mitad corresponden, de forma genérica, a actuaciones de promoción y participación social. Y el coste por usuario oscila de entre 1.000-5.000 pesetas en Aragón, Islas Baleares, etc., a las 20.000-25.000 pesetas en La Rioja y Madrid, con excepción de 71.183 pesetas en Asturias.

Las Ayudas Económicas, que tienen que ver con la atención a las situaciones de emergencia social, han sido de 5.743.041.258 pesetas, lo que supone un coste medio por perceptor de 32.269 pesetas. 
Las actuaciones destinadas al fomento de la solidaridad y la cooperación social tienen que ver con la promoción y organización del voluntariado, la autoayuda y la participación social. Han sido subvencionadas 4.131 entidades con un coste de 2.201.415.758 pesetas, habiéndose realizado (sin contabilizar Cataluña) 10.680 actuaciones. Lo que han realizado un total de 8.983 voluntarios (35,12 por 100 en Andalucía, 19,50 por 100 en Castilla-La Mancha, 23 por 100 en Castilla León y 10,65 por 100 en Galicia) han sido 4.723 actividades de voluntariado, cuyo coste total ascendió a 77.083 .100 pesetas.

Los 17 Albergues (con 574 plazas de dormitorio) y los 21 Centros de Acogida (con 522 plazas para mujeres, menores y polivalentes) alcanzan un coste que oscila entre las 650.000-700.000 pesetas en Canarias y Galicia y las 1.500 .000 pesetas de Andalucía.

- Flexibilidad de servicios (Equipamientos complementarios): según el acuerdo de 1995 de flexibilización de las prestaciones básicas, algunos equipamientos complementarios a los Centros de Servicios Sociales en 1999 se tenía previsto que fueran los siguientes:

2 Comedores Sociales en Andalucía.

9 Pisos Tutelados.

10 Minirresidencias.

57 Oficinas o Servicios de Información.

157 Centros de Estancia Diurna.

Se trata de equipamientos complementarios de los que disponen las siguientes Comunidades Autónomas: Andalucía (54), Asturias (1), Canarias (33), Cataluña (32), Murcia (11) y C. Valenciana (104). La poblaciónn que atienden es, sobre todo, de la tercera edad (clubes y hogares).

- Por Comunidades Autónomas: el número de Centros de Servicios Sociales, Albergues y Centros de Acogida alcanza el 19,8 por 100 del total en Andalucía y el 20,3 por 100 en Galicia, siendo el resto de porcentajes inferior al 8 por 100 en Canarias, Cataluña y Extrenadura (Memoria del 98).

- Castilla-La Mancha y Valencia: son las Comunidades en las que los porcentajes de población de cobertura por los Centros de Servicios Sociales son menores: 63,70 y 62,18 por 100 , respectivamente (Memoria del 97).

- Cataluña: destaca como aquella Comunidad que gasta en el personal (2.996 trabajadores) de todos sus Centros de Servicios Sociales el 25,46 por 100 , en mantenimiento el 40,01 por 100 y el 16,01 por 100 en prestaciones. Sí reparamos en Andalucía, cuyos porcentajes sobresalen sobre el resto, gasta en personal (4.468 trabajadores) el 23,87 por 100, en mantenimiento el 19,83 por 100 y en prestaciones el 20,40 por 100 (Memoria del 97). 


\section{TABLA 7}

Datos sobre categorias estructurales y equipamientos (máx. y mín. por algunas CC.AA.)

\begin{tabular}{lll}
\hline Categorías estructurales & \multicolumn{1}{c}{ Máximos por CC.AA. } & \multicolumn{1}{c}{ Mínimos por CC.AA. } \\
\hline Cobertura & 28.536 hab./UTS en Madrid. & 2.647 hab./UTS en Extremadura. \\
& 80 municipios/proyecto en Castilla & $1-5$ municipios/proyecto en Andalu- \\
& y León. & cía \\
& +70.000 hab./proyecto CSS en Cata- & -13.000 a 20.000 hab./proyecto CSS \\
& luña, La Rioja o Madrid. & en Aragón y Canarias. \\
\hline Gasto & 2.501-3.000 ptas/hab. en Castilla-La & $1.000-1.500$ ptas./hab. en Cantabria \\
& Mancha y Castilla y León. & y Madrid. \\
\hline Trabajadores & 4.001-4.500 hab./trabajador en & 500-1000 hab./trabajador en Galicia. \\
& Madrid. & Salario/trabajador: 2-3 millones en \\
& Salario/trabajador: 3-4 millones en el & Baleares, Cantabria y C. Valenciana. \\
& resto de CC.AA. & \\
\hline
\end{tabular}

\begin{tabular}{ll}
\hline \multicolumn{1}{c}{ Equipamientos } & \multicolumn{1}{c}{ Máximos por CC.AA. } \\
\hline Información & $17,25 \%$ de usuarios de la Comunidad \\
& sobre el total (2.451.999) en Andalucía. \\
& 1.000 ptas./usuario en La Rioja y \\
& Cantabria
\end{tabular}

Cifras menores y minimos por CC.AA.

Apoyo a la Unidad $19,86 \%$ de los 203.414 usuarios en

Convivencial Castilla y León.

y SAD 239.420 ptas./usuario en Cantabria.

Gestión: concertada (33\% en Andalucía) y contrato empresa lucrativa (31\% en Andalucía).

$13,04 \%$ de usuarios de la Comunidad sobre el total en Cataluña.

500 ptas./usuario en Baleares, Canarias y Murcia.

$12,09 \%$ de los 203.414 usuarios en Andalucía.

23.292 ptas./usuario en La Rioja.

Gestión: concertada (10\% Castilla-La Mancha) y contrato empresa lucrativa (12\% Canarias).

Alojamiento

Alternativo

$37,75 \%$ de los 97.508 usuarios en Andalucía.

50.000-60.000 ptas./usuario en Canarias y Madrid (650.000/usuario en Cantabria).

Prevención e Inserción Social
$26,50 \%$ de 1.151 .013 usuarios en Andalucía.

20.000-25.000 ptas./usuario en La Rioja y Madrid (71.183/usuario en Asturias).

\begin{tabular}{ll}
\hline Ayudas & $33,8 \%$ de 5.743 .041 .358 ptas. en \\
Económicas & C. Valenciana.
\end{tabular}

Fomento de la solidaridad y cooperación social

\section{$52,49 \%$ de 4.723 actividades en} Andalucía (37,36\% de 77.083.100 ptas. de coste).

$35,12 \%$ de 8.983 voluntarios en Andalucía.

42,42\% de 2.201.415.758 ptas. de gasto en Andalucía (1.301 entidades).

Albergues y
Centros de Acogida

1.000.000-1.200.000 ptas./plaza albergue en Aragón (1.500.000 en Andalucía). 6.000.000 ptas./plaza Centro para Mujeres en Aragón.
$18,10 \%$ de los 97.508 usuarios en Cataluña.

10.000 ptas./usuario en Aragón, Baleares.

$21,81 \%$ de 1.151 .013 usuarios en Castilla-La Mancha.

1.000-5.000 ptas./usuario en Aragón e Islas Baleares.

$18,81 \%$ de 5.743 .041 .358 ptas. en Andalucía.

$13,15 \%$ de 4.723 actividades en Castilla y León (12,53\% de 77.083.100 ptas. de coste).

19,50\% de 8.983 voluntarios en Castilla y León.

$14,23 \%$ de 2.201 .415 .758 ptas. de gasto en Castilla y León (1.166 entidades); y $14,26 \%$ de 2.201 .415 .758 ptas. de gasto en Murcia (300 entidades).

650.000-700.000 ptas./plaza albergue en Canarias y Galicia. 
- Extremadura, Aragón, La Rioja y Castilla-La Mancha: los gastos por prestaciones alcanzan los porcentajes más altos y numerosos en las ayudas a domicilio (89 por 100 en Extremadura, 67 por 100 en Aragón) e inserción social (35 por 100 en La Rioja y Castilla-La Mancha). Llama la atención que el 39 por 100 lo dedica Cantabria a Información y Orientación, mientras que Valencia dedica el 51 por 100 y La Rioja el 46 por 100 a ayudas económicas ${ }^{35}$.

\section{GRÁFICO 1}

\section{Gastos en prestaciones y en personal de plantilla del Plan Concertado}

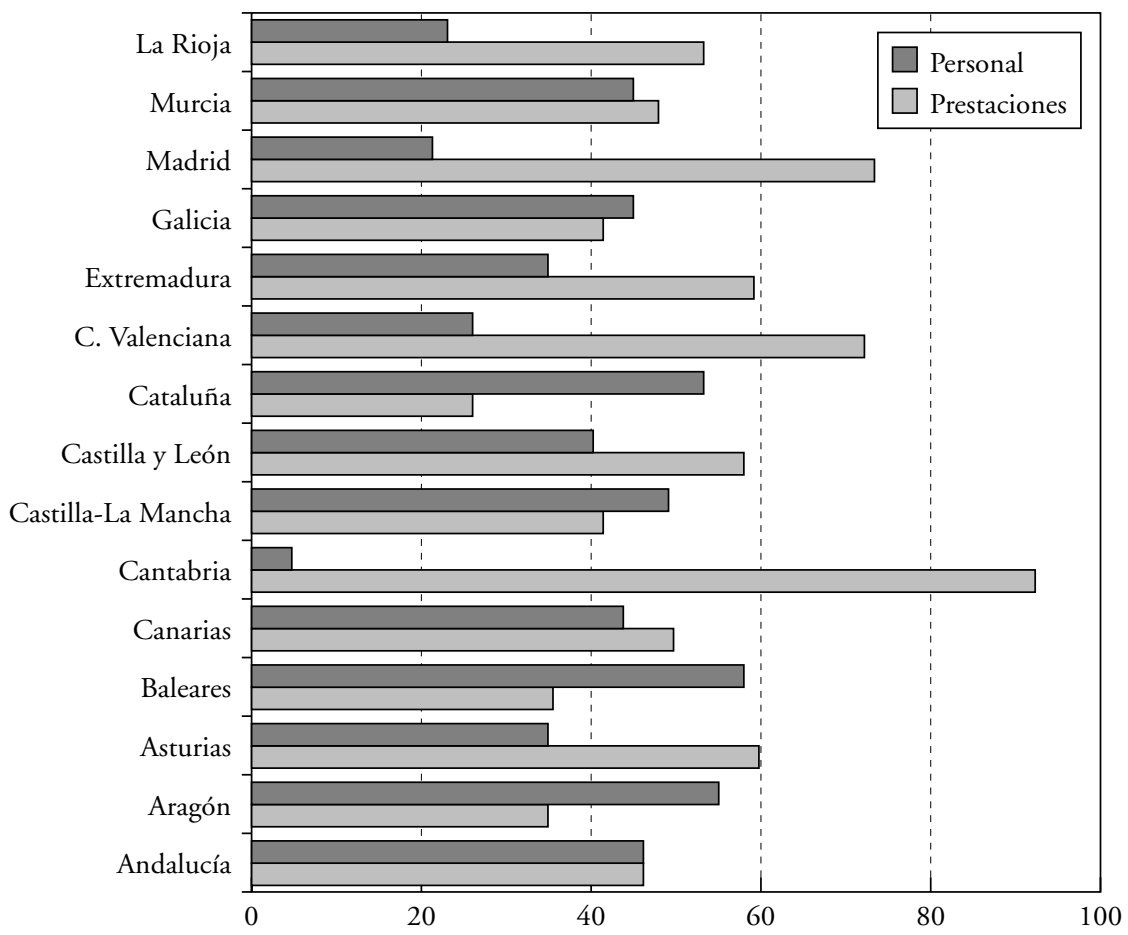

Fuente: Anuario del Plan Concertado 96-97.

- Los ratios por población de referencia según Comunidad Autónoma: 58.591,8 (P.R./Tra.) en Cantabria y 2.272 (P.R./Tra.) en Baleares. Andalucía tiene un P.R./Tra. de 4.521,1 y Cataluña un P.R./Tra. de 2.887,9. Según la última Memoria de 1997-98, el ratio de población por trabajador es cercano a

35 No aparecen los datos correspondientes a Cataluña en la Memoria del 96-97. 
los 4.000 en referencia a las plantillas y a los 3.000 en los trabajadores de prestaciones (Memoria del 96-97).

\section{- El número de usuarios atendidos por prestaciones básicas y Comunidades} Autónomas según los porcentajes más altos es: en Información y Orientación, del 51,69 por 100 pob. en La Rioja, 17,67 por 100 pob. en Extremadura, 14,53 por 100 pob. en Castilla-La Mancha y 12,18 por 100 pob. en Galicia; en Apoyo a la Unidad Convivencial y Ayuda a Domicilio: 1,22 por 100 pob. en Castilla y León, 0,94 por 100 pob. en Castilla-La Mancha y 0,76 por 100 pob. en Canarias; Alojamiento Alternativo: 0,64 por 100 pob. en Aragón y 0,61 por 100 pob. en Andalucía; Actuaciones específicas de Prevención e Inserción: 18,21 por 100 pob. en Castilla-La Mancha, 4,32 por 100 pob. en Andalucía y 4,09 por 100 pob. en Valencia (Memoria 97).

- La ocupación en porcentajes de los albergues (dormitorio y comedor) no sobrepasa el 61 por 100; no obstante, se llega al 143 por 100 (comedor) en Castilla La-Mancha y al 78 por 100 (comedor) en Galicia. Si nos referimos a los Centros de Acogida los porcentajes de ocupación son más altos (69 por 100): el 125 por 100 (dormitorio) en Madrid y el 87 por 100 (dormitorio) en Baleares; el 289 por 100 (comedor) en Madrid y el 95 por 100 (comedor) en Andalucía (Memoria 96-97).

- El coste medio de plaza de dormitorio para los Centros de Acogida (mujer, menor, acogida polivalente) y albergues según cada Comunidad Autónoma varía notablemente de una Comunidad a otra: 4.898 .129 en Andalucía y 353.075 en Cantabria (Memoria 96-97) ${ }^{36}$.

\section{CAMBIO DE RUMBO EN LAS PRESTACIONES BÁSICAS (REPERCUSIONES E IMPLEMENTACIÓN)}

El Plan Concertado apunta a ser un Plan Concertado de Servicios Sociales Integrados porque la red de servicios sociales básicos necesita presentarse con nuevas ofertas a un mayor número de personas necesitadas de tales prestaciones. Y precisamente se ha de salir del estancamiento que han sufrido los recursos-equipamientos básicos del Plan, tales como los llamados Centros de Servicios Sociales, los Albergues y los Centros de Acogida.

Hablar de servicios sociales integrados significa algo más que un concepto al uso para aglutinar servicios sociales de muy diversa índole. Integrar servicios supone sumar inversiones y usuarios que por compartir espacios con otras

36 En este apartado sobre el Análisis y Valoración del Plan Concertado es aconsejable tener en consideración el trabajo de Miguel López-CABANAS (1997), Sistemas de Registro en Servicios Sociales Comunitarios, Universidad de Málaga. 
redes (sanitarias, educativas, p.ej.) pueden llegar a disminuir el coste final, entre otros efectos.

Un posible cambio de rumbo en el Plan Concertado nos obliga a tener presentes los datos aportados y, sobre todo, a hacer algunas propuestas, basadas precisamente en la experiencia de más de doce años recorridos.

\subsection{Propuestas}

- El Plan Concertado de Servicios Sociales Integrados está en condiciones de fijar los objetivos a conseguir a corto, medio y largo plazo: creación y consolidación de equipos, establecimiento de prioridades, análisis de necesidades-recursos y satisfacción no sectorializada de las expectativas sociales generadas por el mismo. En consecuencia, se ha de aumentar la complejidad de los equipos, actualizar los mapas de las necesidades y satisfacer la demanda real de servicios según los estudios realizados. En esta línea, la última Memoria del Plan del año 1998-99 ya indica en su presentación que se trabaja en una investigación que evalúa el impacto del Sistema Público de Servicios Sociales de Atención Primaria en el ámbito de los territorios autonómicos. Y más específicamente en un análisis de la situación de la "Atención Domiciliaria», para evaluar su realidad y trascender al diseño de un Plan estatal en esta materia.

- El Plan Concertado, que constituye una red, no tiene por qué ser simétrico: puede crecer en función de las necesidades y de la capacidad imaginativa de sus trabajadores si se revisan las condiciones que se estiman necesarias para lograrlo. Para lo cual los equipos de los servicios sociales de base trabajarán en función de los programas que hayan elaborado ajustándose a la realidad existente. Ahora bien, es imprescindible salir del estancamiento en que se encuentran los equipamientos referidos a los llamados Centros de Servicios Sociales, los Albergues y los Centros de Acogida.

- Como red básica de servicios sociales integrados, el Plan Concertado puede progresar en complejidad para ser capaz de sustentar y apoyar servicios sociales especializados de mayor demanda: viviendas tuteladas, residencias, centros de día, unidades sociosanitarias para enfermos crónicos y terminales (de fisonomía normalizada y reducido número de plazas). Únicamente de este modo los servicios sociales de base pueden coordinar y apoyar servicios especializados (sociosanitarios, terminales en domicilio, residenciales para mayores) que requieren de su concurso. En caso contrario, la separación entre los servicios sociales especializados y los de base es insalvable. Las consecuencias ya se hacen notar: sobreabundamiento de las responsabilidades familiares y, en última instancia, el ingreso en un espacio residencial.

- La creación y consolidación de los equipos de profesionales puede irse vinculando a la obtención de resultados y consecución de programas, procurando estar abiertos a la posibilidad de que sean multiprofesionales. La propia complejidad de los problemas sociales lo exige, así como el aconsejable modo 
de trabajar interdiciplinar para cubrir desde los diversos sistemas los problemas que padecen los usuarios. Inmediatamente añadiremos la necesaria puesta a punto de los profesionales en formación y, sobre todo, de ir poniendo en práctica métodos que permitan medir y evaluar razonablemente el posible progreso o mejora de lo que se viene haciendo.

- Si la financiación puede aumentarse vía servicios sociales específicos y especializados pero integrados, no desechar la oportunidad de vincularlos a los servicios sociales de base como red de apoyo de los primeros. Posiblemente sea más fácil técnicamente invertir en determinados servicios especializados (plazas residenciales para mayores, enfermos de Alzheimer) que en otro tipo de servicios intermedios o más básicos (centros de día, ayuda a domicilio, teleasistencia). La inversión en servicios sociales especializados será, probablemente, más rentable si cuenta con el apoyo de servicios sociales complementarios. Se trata, en definitiva, de combinar dos principios razonables: abaratar los costes finales y, sobre todo, humanizar los servicios sociales prestados, tratando de mantener a los usuarios en contacto con el contexto propio.

- Sin abandonar lo que son los servicios sociales de base, se puede estudiar el desarrollo de programas más complejos para aquellas prestaciones que se presentan con escasa definición: integración o apoyo a la solidaridad, entre otros. La utilización de estos dos conceptos (integración y solidaridad) ha de exigir mayor precisión en materia de servicios sociales. Se requieren proyectos específicos que demuestren de hecho la integración posible en determinadas circunstancias, así como de un apoyo y coordinación de la solidaridad civil. Ahora bien, no siempre queda claro que los usuarios han de participar y esforzarse por hacer «lo que plantean los servicios sociales», o que la responsabilidad pública ha de profundizar en sus esfuerzos sin dar pie a que la solidaridad rebaje las exigencias de la Administración. Luego los principios del esfuerzo y la participación de los usuarios en servicios sociales, así como el apoyo a la solidaridad, no han de disminuir la efectividad y responsabilidades públicas.

- Las prestaciones ofertadas desde el Plan Concertado pueden mostrar un perfil más decidido a la hora de apoyar y no sustituir las redes de intercambio normalizadas de los usuarios (familia, colegio, trabajo); apoyo a las familias que cuidan de personas mayores. No se trataría de compensarles, por su aportación, con posibles servicios públicos todavía inexistentes, sino de complementar el esfuerzo, hasta cierto punto lógico y comprensible, de determinados miembros de la familia en beneficio de sus mayores. Queda bastante claro que sustituir las redes de intercambio es poco menos que imposible. Sin embargo, es necesario aumentar y diversificar la ayuda a domicilio y aquellos servicios sociales de apoyo a la familia, precisamente porque es el sector que más demanda Información y Ayuda a Domicilio (SAD). Es bien conocido que las responsabilidades familiares tienen que ver con los hijos y mayores, de tal modo que han de combinarse espacios familiares, escolares y laborales. Sin embargo, apenas si existen servicios sociales de apoyo e intermedios para apoyar el bienestar de las familias. 
- Los servicios sociales integrales de la red básica, aun manteniendo el carácter público, pueden combinarse con módulos de pago (viviendas tuteladas o ayuda a domicilio, p.ej.) y gestión privada con y sin ánimo de lucro. Sin menoscabo de la responsabilidad pública de los servicios, es posible aumentar la calidad de los mismos con la participación económica proporcional de los usuarios y hacerla extensiva a un mayor número de personas. También es posible abaratar los costes controlando los resultados de la gestión (con y sin ánimo de lucro), al mismo tiempo que se publican los Anuarios correspondientes para que exista un mayor control público.

- El Plan Concertado puede desarrollarse también en la línea de asumir responsabilidades como evaluar el apoyo económico, incentivos fiscales, etc., por cuidar en la familia de personas mayores, hijos menores de tres años y personas dependientes. Son necesarios servicios sociales de apoyo a la familia (guarderías, comedores, ayuda a domicilio puntual y sistemática) en España ante la escasez de los mismos; y precisamente la familia es el sector que más servicios sociales demanda de Información y Ayuda a Domicilio. También la Ley 39/99, de 5 de noviembre, sobre conciliación familiar y laboral, ha permitido avanzar con los permisos de formación, maternidad/paternidad, lactancia, embarazo, parental o atención familiar. Sin embargo, los servicios sociales de base pueden progresar, tanto en los servicios sociales para las familias normalizadas como para las situaciones de violencia familiar, en situaciones de riesgo social, monoparentales y de orientación-mediación.

- Se reúnen las condiciones para fomentar desde el Plan Concertado una cultura de la complementariedad de roles profesionales, capaz de desarrollar programas complejos en espacios propios o compartidos y con horarios flexibles. Se trata de hacer posible la combinación entre profesionales (atención primaria de salud, centros de enseñanza y empresas) para abordar necesidades sociales complejas en programas compartidos. También va siendo necesario valorar la posibilidad de contemplar horarios que pueden verse ampliados porque las ocasiones lo requieren. En su defecto pueden establecerse horarios de guardia o de urgencia.

- Se puede estudiar la posibilidad de cambios de lugar y función entre el personal de plantilla del Plan Concertado. El objetivo no es otro que el de fomentar la creatividad y la motivación profesional. Es conveniente estudiar aquellos criterios con los que valorar a los profesionales, posibilitando su traslado y cambio de funciones cada cierto tiempo (cuatro años, p.ej.).

- Es importante que desde el Plan Concertado se favorezca una cultura imaginativa-innovadora y transformadora de la comunidad, revalorizando lo propio y tradicional de cada pueblo, comarca y barrio. De este modo adquiere un valor añadido el propio Plan Concertado. Es imprescindible que los servicios sociales de base o comunitarios participen en aquellos programas, tanto de turismo rural como en los más propios para satisfacer las necesidades básicas. No podemos olvidar la realidad rural-municipal en España de tantos municipios muy pequeños y hasta en situación de desaparición. 
- Ensayar la posibilidad de coordinar y suprimir procesos burocráticos de otras administraciones, así como conjuntar los equipos y presupuestos correspondientes, podría ser un reto a conseguir progresivamente. Se debe intentar la informatización, una vez sepamos el coste económico y el tiempo de determinados procesos burocráticos. También merecería la pena el estudio de las dificultades técnicas que dificultan conjuntar equipos y presupuestos, para avanzar en servicios sociales sociosanitarios, socioeducativos y sociolaborales.

- Recuperar-afianzar por parte de los profesionales el contacto directo con la gente que confía en ellos, y en muchos casos la única referencia de responsabilidad y eficacia pública que puede ser un logro inestimable (escuchar a la gente). En esta línea es aconsejable potenciar programas con participación social, tanto con jóvenes como con mujeres y entre personas mayores.

- Tratar de conseguir que la investigación y formación, en materia de servicios sociales generales, corra a cargo de uno o varios proyectos coordinados desde la Universidad y con resultados bianuales. Es un modo de hacer viables determinados objetivos y de medir procesos y resultados. Se debe perseguir y lograr la máxima objetividad científica y, desde luego, la capacidad técnica para transformar los problemas.

- La futura identidad de los servicios sociales de base parece exigir un aumento de los usuarios, conocimiento de la satisfacción de los mismos e investigación-innovación sobre necesidades reales de la población (actualización de «mapas»). Aunque la cobertura de municipios y población es muy elevada, no quiere decirse que los ciudadanos están en las mismas condiciones de acceder a los servicios sociales. Se requiere difundir los servicios y saber sobre la satisfacción de quienes los usan, así como aumentar el número de usuarios, porque estamos hablando de prestaciones básicas.

- Es conveniente conocer y ayudar a la renovación de los Planes Integrales Municipales para modificar y poner a punto los mapas sobre las necesidades de cada Comunidad Autónoma.

- Sería deseable que los Servicios Sociales Integrales formaran parte del diseño más amplio de servicios en general, en función del hábitat, espacio, productividad competitiva y conexiones territoriales, según el caso de cada unidad territorial. El camino de los servicios sociales comarcales parece abrirse paso y es una vía que debe aprovecharse, teniendo en cuenta el desarrollo jurídico correspondiente (Aragón y Cataluña).

- Intentar el acceso a las radios y medios de comunicación locales por parte de los equipos de los Centros constituiría una experiencia a evaluar. El objetivo no es otro que alcanzar mayor difusión de los objetivos y estrategias profesionales en materia de servicios sociales integrales. Es importante difundir lo que se hace profesionalmente y estar dispuesto a recibir las críticas

- Los servicios sociales de base pueden colaborar en la creación de puestos de trabajo, integrando las posibilidades de los espacios rurales y ofertando servicios de ocio, cultura y deporte (recuperación de los espacios rurales). El propio Plan necesita incrementar el número de sus trabajadores para afrontar 
la satisfacción de las necesidades básicas. Y debe colaborarse en servicios sociales de ocio, cultura y deporte para aumentar el bienestar de colectivos que lo requieren: personas mayores, discapacitados y mujeres.

- Estudiar el trasvase de mayores recursos desde la Administración Central, Autonómica y Comarcal a los municipios en función de criterios combinados: número de habitantes y capacidad innovadora de los equipos profesionales y comunidad local, por ejemplo. El objetivo apunta a compensar el esfuerzo de los equipos, así como su capacidad innovadora, según las peculiaridades de cada comarca o municipio.

- La red de servicios sociales integrales de base puede convertirse en el principal apoyo informativo-formativo del voluntariado-asociaciones. No se trata de abaratar costes, ni de disminuir la responsabilidad pública; se trata de apoyar la cultura de la solidaridad civil, ofreciendo información y formación desde la propia red.

\section{BIBLIOGRAFÍA}

Aguilar, M. (1990): «Una docena de mitos, síndromes, límites y mistificaciones acerca de los servicios sociales y el Trabajo Social», Rev. Documentación Social, núm. 79.

Alemán Bracho, C., y Garcés Ferrer, J. (1996): Administración social: servicios de bienestar social, Siglo XXI, Madrid.

- (1998): Politica Social, McGraw-Hill, Madrid.

CANal, J. (1991): "Comunidad y redes sociales: de las metáforas a los conciertos operativos», Rev. Servicios Sociales y Politica Social, núm. 23.

Cáritas Española (1965): Plan CCB, Ed. Euramérica, Madrid.

Casado, D. (1969): Plan Social Baza, Ed. Cáritas Española, Madrid.

Del Valle, A. (1966): «La promoción urbana y sus objetivos», Rev. Documentación Social, núm. 1.

Doménech, R. (1981): «Servicios sociales para todos», Rev. Documentación, núm. 44.

Duocastella, R. (1958): "Necesidad de una "Acción Social” en Cáritas Diocesanas», Rev. Documentación Social, núm. 1

Esping-Andersen, Gosta (1998): «El Estado de Bienestar», en Tomás Fernández García (coord.), Estado de Bienestar: perspectivas y límites, Colección Estudios, Ediciones de la Universidad de Castilla-La Mancha.

Fernández, P. (1983): «Política Social», Rev. Documentación Social, núm. 53.

GARCÍA, J. L. (1988): España. Economía, 2 vols., Ed. Espasa-Calpe, Madrid.

GaViria, M., Laparra, M., y AgUilar, M. (1992): «Los servicios sociales generales. Un sistema sin objeto» (en coop.), Evolución social en España (1990), Instituto Sindical de Estudios, Madrid.

Gutiérrez ResA, A. (1997): Acción Social No Gubernamental, Tirant Lo Blanch, Valencia.

Gutiérrez Resa, A., y Garcés Ferrer, J. (2000): Los Servicios Sociales en las Comunidades y Ciudades Autónomas, Tirant Lo Blanch, Valencia.

López-Cabanas, M. (1997): Sistemas de Registro en Servicios Sociales Comunitarios, Universidad de Málaga, Estudios y Ensayos, Servicio de Publicaciones, Málaga.

Ministerio de Trabajo y Asuntos Sociales (1988-1997): Memorias del Plan Concertado de Prestaciones Básicas de Servicios Sociales en Corporaciones Locales, Secretaría General de Asuntos Sociales, Madrid.

- (1997): El Sistema Público de Servicios Sociales, Secretaría General de Asuntos Sociales, Subdirección General de Publicaciones, Madrid.

- (1998): Catálogo de Prestaciones de Servicios Sociales de Atención Primaria, Secretaría General de Asuntos Sociales, Madrid. 
NaVArro, F. J. (1979): «El bienestar social y los servicios sociales. Concepto y organización», Rev. Documentación Social, núm. 36.

Riechmann, J. (coord.) (1998): Necesitar, desear, vivir. Sobre necesidades, desarrollo humano, crecimiento económico y sustentabilidad, Los Libros de la Catarata, Madrid.

SÁnCHEZ, C. (EDIS): «Los servicios que debe prestar el municipio», Rev. Documentación Social, núm. 29.

- (1979): «El bienestar social a través de la historia y su concepto actual», Rev. Documentación Social, núm. 36.

VILlota, F. (1973): Problemas actuales de los servicios de bienestar social, Ed. Fundación FOESSA, Euroamérica, Madrid.

VV.AA. (1988): «Sociedad civil y Estado. ¿Reflujo o Retorno de la Sociedad Civil?», Documentos y Estudios, 61, Ed. Fundación Friedrich Ebert, Madrid.

VV.AA. (1992): La sociedad de la desigualdad, Ed. Garkoa, San Sebastián.

Congreso (Primero) Nacional (1994): El Sistema Público de los Servicios Sociales en la Administración Local, A Coruña (24 de marzo).

Curso (1998): Evaluación del Plan Concertado de Servicios Sociales, diez años después, Guadix (Granada, 10-21 de noviembre).

VII Jornadas Nacionales (1998): VII Jornadas Nacionales de Servicios Sociales en el Medio Rural, Jaca (Huesca, 22-24 de octubre). Dipugación de Zaragoza (Bienestar Social).

\begin{abstract}
The intervention of public authorities through State bodies has been a constant factor in respect of social welfare and social services, and now that the $20^{\text {th }}$ century has ended we consider it appropriate for the State to continue being the fundamental guarantee for those individuals who, together with the market and, above all, non profit-making organizations, are going through difficult times. The CCB Plan (Christian community of assets) was the source of inspiration of basic or community social services in the sixties. It was the Spanish tradition that was closest to hand and capable of organizing such services for providing social welfare and charity. As from the reinstatement of democracy and for several years after this (1988) a public network of general social services for everyone began to develop, and this started becoming consolidated during the nineties on the level of basic benefits. The agreement reached between the Central Administration, Autonomous Regions and Local Bodies was to make the establishment of the basic network of public social services possible. The 1988 «Plan Concertado» (Officially Approved Plan) was the product of that agreement, and this became consolidated in around 1995. Now that over ten years have elapsed since the "Plan Concertado" saw the light of day (1988-1998), the experience gained and the information now available make it possible to bring in transformatioins which adapt it to the new needs of Spanish society. The demands made by fresh needs and social services for everyone set the standards for what the advancement of the «Plan Concertado» should be.
\end{abstract}


NOTAS DE INVESTIGACIÓN 